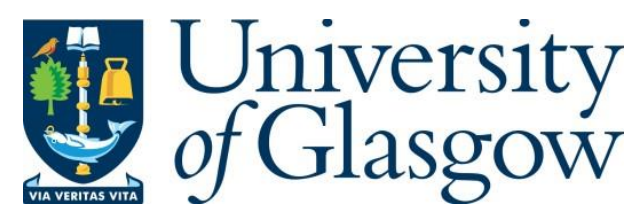

Meena, N. K., Yang, J. and Zacharis, E. (2019) Optimisation framework for the design and operation of open-market urban and remote community microgrids. Applied Energy, $252,113399$.

There may be differences between this version and the published version. You are advised to consult the publisher's version if you wish to cite from it.

http://eprints.gla.ac.uk/201571/

Deposited on: 25 October 2019

Enlighten - Research publications by members of the University of Glasgow http://eprints.gla.ac.uk 


\title{
Optimisation Framework for the Design and Operation of Open-Market Urban and Remote Community Microgrids
}

\author{
Nand K. Meena ${ }^{\mathrm{a}, *}$, Jin Yang ${ }^{\mathrm{a}, * *}$, Evan Zacharis ${ }^{\mathrm{b}}$ \\ ${ }^{a}$ School of Engineering and Applied Science, Aston University, Birmingham, B4 7ET, United Kingdom \\ ${ }^{b}$ Hypertech SA ,32 Perikleous st., Halandri, Attica, Greece
}

\begin{abstract}
In this article, a new business model considering multiple stakeholders is proposed to develop a framework for third-party investment and future flexible retail electricity market in community microgrids. The proposed two-stage optimisation platform generates opportunities for multiple stakeholders to invest in the design of community microgrids, comprising multiple and different distributed energy resources such as renewable generation units, battery energy storage systems, and micro diesel engines, to minimize daily operational costs of the system. To proliferate the prosumers in retail energy markets as per the Office of Gas and Electricity Markets, United Kingdom, a peer-to-peer energy trading and energy management scheme is also proposed. The optimal sizing of urban and remote community microgrids are determined in stage-1, followed by their optimal operations to minimise the daily operating cost of the community system in stage-2. An improved version of the genetic algorithm is employed to optimise decision variables in both the stages. Different cases are investigated which show the tremendous potential of revenue generation for all stakeholders while effectively optimizing techno-economic operations of microgrids.
\end{abstract}

Keywords: Battery energy storage system; community microgrid; distributed energy resources; genetic algorithm; microgrid; P2P energy trading, renewables;

\section{Introduction}

According to a report, published by Population Division of the United Nations Department of Economic and Social Affairs in 2017, the global population of 7.7 billion is expected to reach 8.6 billion in 2030, 9.8 billion in 2050 and 11.2 billion in 2100 . In the contemporary world, energy is the basic need for survival too, as water and food, which increases with

\footnotetext{
*Corresponding author(s): Nand K. Meena

E-mail address: n.meena@aston.ac.uk

${ }^{* *}$ Corresponding author(s): Jin Yang

E-mail address: j.yang8@aston.ac.uk
}

The short version of the paper was presented at REM2018, September 28-30, Rhodes (Paper ID: 124). This paper is a substantial extension of the short version of the conference paper.

Preprint submitted to Elsevier 
population. The annual energy consumption is correlated to the gross domestic product (GDP), since it defines the living standard and development of a country.

In-spite of many powerful economies across the globe, there are people who still don't have access to clean energy for fulfilment of their basic needs, i.e., food, heating and lighting. Many people and communities across the globe still rely on fossil fuels such as wood and kerosene to prepare their food which adversely affects the nutrients and causes pollution. According to an IEA report in 2010, 2.4 billion population depends on biomass fuels which will increase to 2.7 billion by 2030, in absence of substantial changes in current policies [1]. A recent case study [2] shows that the majority of people in Northwest Ethiopia use traditional fuels for cooking due to some beliefs and lack of knowledge about modern infrastructure. According to a world bank's report 'sustainable energy for all (SE4ALL)' 2016, 12.63\% of world's population does not have access to electricity. As per this data [3], the access to electricity in some countries are very poor even less than 20\% such as Burundi (7.59\%), Chad (8.83\%), South Sudan (8.95\%), Malavi (11\%), Central African Republic (13.99\%), GuineaBissau (14.66\%), Niger (16.22\%), Congo, Dem. Rep. (17.15\%), Burkina Faso (19.16\%) and Liberia (19.80\%).

In Canada, approximately 239 communities, mostly scattered across northern areas, with large access to abundant clean energy resources, have no connection to grid [4]. These communities depend on conventional fuels, transported over winter roads, water, and by air, to generate electricity and home heating. There are approximately 4 million population living in north of the Arctic Circle where communities vary from a few dozens to more than 100,000. Many communities across northern Canada and Alaska conventionally rely on diesel generators where fuel delivery through ice can be difficult and expensive [5]. According to an estimation performed by Magda Moner-Girona, the European Commission, diesel engines (DEs) are commonly used source to supply electricity in such communities, with a combined installed capacity of 10,000 MW globally due to their high reliability and low investment with mature technologies [6]. Although DEs are associated high operating costs, environmental impacts, and difficult fuel logistics. In-spite of having ample renewable energy potential, the electricity supplied to the mining industry in Ghana is cost intensive, especially in remote areas [7]. As investigated in [8], approximately $22 \%$ population of Nicaraguan do not have access to electricity but the disperse availability of RERs has proliferated the off-grid community microgrids across the country.

In developing countries, e.g, Sub-Saharan Africa, the transmission system is geographically limited and daily per capita use of electricity is about $1-2 \mathrm{kWh}$, when averaging for entire country population [9]. In north-eastern region of India, there are many communities living in hilly areas where power transmission is not possible due to heavy rainfall, long forest trails, and mountains. The region includes eight states, including Sikkim, Tripura and Nagaland, have 1700 un-electrified villages by July 2017 [10]. To estimate the growing energy deficiency and to make a future pathway to energy for all by 2030, the IEA has been doing continuous efforts across the world, for nearly twenty years [11]. The majority of member states, the United Nations agreed, in 2015, for the sustainable development across the globe, i.e., access to electricity and clean cooking. For the first time in 2017, the world's population without electricity dropped below one billion, as published in 'World Energy 


\section{Outlook 2018'.}

At present, the main goal is to meet the growing global energy demand while minimizing the greenhouse gases emission, which are conflicting objectives when we have large sharing of conventional power plants. According to the World Energy Balance, 2018, the demand for energy sources that may include oil, coal and gas will grow therefore, the days of cheap energy are unlikely to return [12]. To limit the impact of accelerative energy price, substantial investments in sustainable alternatives such as renewables and nuclear are very much required. The share of clean energy technologies has to increase at a faster rate. Governments across the globe are working together to increase the share of renewables in total primary energy supplied. In the last five years, the energy sector investment in clean energy technologies is exploded. It has been estimated that by $2050,80 \%$ of the global energy demand would be supplied by renewables only, if sufficient infrastructure and policies are adopted [13]. The key issues with renewables such as solar and wind are to deal with their intermittent and distributed nature. On the other hand, the existing electrical infrastructure is not capable to accommodate high renewable penetration and further investment in new electrical infrastructure may not be cost effective. In this situation, various supporting dispatchable energy resources along with advanced information and communication technologies may be propitious. These alternative solutions can be centralized (e.g., nuclear and hydro-power) or distributed (e.g., pumped-hydro, gas-turbines, energy storage, etc.). The modern power industry is transforming from centralized to distributed energy systems with more sophisticated technologies in deregulated environment.

The renewable energy resources are dispersed in nature therefore local utilisation of these resources is propitious and encouraged. Nowadays, small-sized renewable based distributed generations (DGs) are integrated in distribution systems. However, traditional distribution networks are passive in nature which were not designed to accommodate high renewable penetration. A non-optimal sizing of intermittent DGs may affect system stability [14] and security [15]. To limit some of the issues, active distribution systems are proliferating in modern power systems. The DGs are optimally deployed by investigating multiple possible scenarios of the system and energy resources. On the other hand, the optimal integration of DERs minimizes power/energy loss [16], emission [17], node voltage deviation [15], cost of network up-gradation, investment and various operating costs while improving reliability [18] and stability [16] of distribution systems. Despite of these benefits, the growth of active distribution systems is limited by certain factors. These can be ageing infrastructure, lack of monitoring and control schemes, unidirectional power flow design \& protection schemes, limited load demand control, limited hosting ability of renewables, no islanding ability, poor security, reliability, and resiliency, etc.

To overcome some of the limitations of active distribution system, the concept of microgrid is one of the alternatives with an ability to manage high renewable generation within small-scaled electrical boundaries. Further, it allows consumers to have more choices and flexibility to manage their energy consumption and cost with enhanced reliability [19]. A microgrid is designed by inclusion of local energy resources and can be the part of distribution system, i.e., grid-connected microgrid. The US Department of Energy (DOE) defines the microgrid as a group of interconnected loads and DERs within clearly defined electrical 
boundaries that acts as a single controllable entity with respect to the grid. It should have the capability to operated in grid-connected and islanding modes, in case of upstream grid failure. The DOE stated that microgrid has three major objectives: 1) outage time reduction of critical loads at a cost comparable to non-integrated baseline solution; 2) emission reduction; and 3) efficiency improvement.

Although, the concept is no longer new when looking with energy systems perceptive except contemporary advanced control, information, and communication technologies. The first grid developed in the 19th century was a small-scaled and isolated 'microgrid', supplying the local loads, without the support of any transmission grid which is very similar to contemporary microgrids. The decentralisation of power system along with growing interest in dispersed renewable energy resources, controllable loads, smart switches, BESS, advanced information and communication technologies have developed the concept of modern microgrid [20]. The optimal proliferation of grid-connected microgrids, in presence of high renewable penetration, can improve the performance [21], reliability [22] and resiliency of distribution systems . Similar to active distribution systems, a microgrid is also limited to meet the IEA goal 'global energy for all'. The shortcomings of conventional microgrid may include, single or a small number of consumer involvement, consumer oriented benefits, expensive deployment, limited backup in off-grid mode, limited ability to participate in retain energy markets, etc.

As discussed, gaining access to electricity for some communities across the globe is very challenging either due to geography or economics. Such communities, without electricity access, is only part of the remote energy problem [23]. These communities, across the globe, live in harsh weather conditions therefore, sustainable power transmission infrastructure is challenging and not economical. Apart from remote communities, some of the urban communities are currently facing technical issues which can include feeder congestion during peak load, underutilization of power in off-peak hours, and alarming penetration of renewables [24]. Therefore, there is a constituted need for community microgrids deployment to serve multiple electricity consumers during long-term unavailability of main grid. Community microgrids can connect critical loads and distributed energy resources owned by different stakeholders, thereby presenting significant new design goals, operating constraints, retail markets and business models [25].

The community microgrid can be defined as a small-sized local grid, interconnected to high penetration of renewables, flexible DERs (e.g., BESSs, EVs, DRs, etc.), demand response programs, critical \& non-critical loads of specific community. Such microgrids can manage high penetration of renewables within community boundary and has potential to improve the reliability, scalability, flexibility, sustainability and security of electric grid. These communities can be residential/commercial buildings, shops, schools, resorts, hospitals, etc. The first community microgrid was developed in Bella Coola, British Columbia, Canada that initiated the partial replacement of diesel generators with clean energy technologies [26]. Some of the features of active distribution systems, conventional and community microgrids are compared and presented in Table 1.

In literature, various application scenarios, elements or technologies are investigated to realise cost-effective deployment of microgrids. These can be techno-economic feasibility 
Table 1: Comparison between conventional microgrid, community microgrid, and active distribution systems

\begin{tabular}{|c|c|c|c|}
\hline Feature & $\begin{array}{l}\text { Active distribution sys- } \\
\text { tems }\end{array}$ & Conventional microgrids & Community microgrids \\
\hline Area & $\begin{array}{l}\text { Large area with multiple } \\
\text { substations connected to } \\
\text { it. }\end{array}$ & $\begin{array}{l}\text { Covers single consumer or } \\
\text { small number of community } \\
\text { people in neighbouring loca- } \\
\text { tions. }\end{array}$ & $\begin{array}{l}\text { Usually it covers entire sub- } \\
\text { station area, thousands of cus- } \\
\text { tomers can be benefited. }\end{array}$ \\
\hline DER sites & $\begin{array}{l}\text { Multiple DERs can be } \\
\text { deployed within the sys- } \\
\text { tem }\end{array}$ & $\begin{array}{l}\text { Generally deployed behind } \\
\text { the meters }\end{array}$ & $\begin{array}{l}\text { Installed in front of the meter } \\
\text { (point of common coupling). }\end{array}$ \\
\hline Cost & $\begin{array}{l}\text { Needs high investment } \\
\text { cost }\end{array}$ & $\begin{array}{l}\text { Expensive and generates } \\
\text { more benefit for owner but } \\
\text { little for grid. }\end{array}$ & $\begin{array}{l}\text { Deploying DER more broadly } \\
\text { with less investment and high } \\
\text { scalability. }\end{array}$ \\
\hline $\begin{array}{l}\text { Resiliency } \\
\text { \& security }\end{array}$ & weak & $\begin{array}{l}\text { Facilitate with limited back- } \\
\text { up power supply, mostly sin- } \\
\text { gle consumer. }\end{array}$ & $\begin{array}{l}\text { Able to provides back-up } \\
\text { power, for indefinite time, to } \\
\text { prioritized and critical load of } \\
\text { the community. }\end{array}$ \\
\hline Scalability & Large & $\begin{array}{l}\text { Needed to work at each cus- } \\
\text { tomer level. }\end{array}$ & $\begin{array}{l}\text { Enables easy replication across } \\
\text { community area as distribution } \\
\text { systems. }\end{array}$ \\
\hline $\begin{array}{l}\text { Off-grid } \\
\text { operations }\end{array}$ & $\begin{array}{l}\text { Always operated in con- } \\
\text { junction to main grid }\end{array}$ & $\begin{array}{l}\text { Can operate for limited dura- } \\
\text { tion }\end{array}$ & Indefinite time is possible \\
\hline $\begin{array}{l}\text { Renewable } \\
\text { penetra- } \\
\text { tion }\end{array}$ & $\begin{array}{l}\text { limited penetration is al- } \\
\text { lowed }\end{array}$ & Moderate & $\begin{array}{l}\text { Leverage high penetration of } \\
\text { local renewables }\end{array}$ \\
\hline $\begin{array}{l}\text { Market } \\
\text { models }\end{array}$ & $\begin{array}{l}\text { Usually centrally owned, } \\
\text { with few retailers at cus- } \\
\text { tomer points }\end{array}$ & Single consumer owned & $\begin{array}{l}\text { Usually have multiple stake- } \\
\text { holders }\end{array}$ \\
\hline
\end{tabular}

analysis of DERs, power electronics, control schemes and technologies, optimisations, retail electricity market models, etc., as discussed in following sections.

\subsection{Distributed energy resources}

DERs are the key component, and main source of energy for community microgrids which majorly includes renewable based DGs generally, solar PVs and wind turbines. The dispatchable DERs are also deployed to provide backup power to critical loads first followed by non-critical loads on a priority basis, if excess power is available [27]. The dispatchable DERs may include combined heat and power (CHP), biomass, fuel cells, battery energy storage systems (BESSs), diesel engines, shunt capacitors etc. In the near future, the electric vehicles can also be considered as one of the promising DERs to feed power back to microgrids when needed [28]. The CHP technology can save millions by utilizing the waste energy produced during electricity production. This can be used to heat or cool the building with an efficiency of $80 \%$ whereas, the efficiency of independent heating or cooling systems is typically no more than $45 \%$ [29].

The energy storage system increases the operational flexibility of microgrid when integrated, by the way of its controlled charging during high renewable generation and dis- 
charging in peak demand hours. The key benefits of energy storage can include network investment deferral, minimize the need of conventional peak generation capacity, cost effective bidding targets, maximum utilisation of clean energy technologies, network power balancing etc. [30]. The most popular energy storage technologies deployed worldwide may include solid state battery, flow batteries, flywheels, compressed air, thermal, and pumped hydro, etc. According to Bloomberg's primary research service [31], the global energy storage market is expected to reach 620 billion USD by 2040. The integration of energy storage solutions is proliferated with rapid deployment of renewables. Recently, Tesla and Neoen completed the world's largest 100 MWh Lithium-ion battery installation in Australia [32] which help to store the excess wind power generation during low peak hours and supply back when needed. It also provides ancillary services to the grid.

In literature, various optimisation models have been developed for optimal sizing of community microgrid, aiming to maximize the techno-economic benefits of different stakeholders. In [23], scenarios are developed to analyse, identify and assess the impact of different DER options for urban residential community microgrids. A decision tree-based approach is presented in [33] for the planning of BESS in community microgrids. A co-optimisation scheme is proposed in [34] for optimal planning of DERs in community microgrids, aiming to minimize the annualized cost at the maximum fuel saving. In [35], a community microgrid model is developed for rural development in Kenya.

A hydrogen-powered community microgrid is developed in [24] to meet the community's energy demand up to two days blackout. A mixed-integer linear optimisation based design and operational management model is proposed in [36] by determining the optimal mix of different DERs. In [37], a mixed-integer programming (MIP) based two-level optimisation method is developed to design a tri-generation system to satisfy district heating, cooling, and hot-water demands. A techno-economic feasibility analysis is presented in [7] for off-grid microgrids to supply power to mining industries in remote areas of Ghana. A very similar off-grid microgrid model is investigated in [38], for residential communities living in desert area.

In [39], a community microgrid model is presented in which fuel-cell (hydrogen) based EVs have been supplied power to main grid when parked. Hong et al. [40] have investigated the Markov model for optimal sizing of renewables to maximize the welfare of community microgrids, with different time-of-use tariffs, while maintaining comfortable indoor temperature. The feasibility analysis of a hybrid PV/diesel system is investigated in [41] for Isolated community microgrids in Thailand. Similarly, a community DC microgrid is developed in [42] that supplies electricity to a community in Chiang Mai Rajabhat University, Thailand. The community was comprised of six small houses, an office, mini-mart, coffee shop, restaurant, an organic farm etc. In [43], a long-term renewable-based DG planning model is proposed, by considering the characteristics of diesel generators, for remote communities in Canada.

\subsection{Power electronics, control, optimisation and management schemes}

Nowadays, the switched mode power supply is widely adopted at different stages in control and optimisation of power systems [44]. The different DERs are interfaced with 
power electronics converter when connected to power networks. With the help of maximum power point tracking (MPPT) algorithm, the maximum power generation, from solar PV systems, can be ensured in uncertain weather considerations which is basically optimizing the converter parameters. However, these converters can pollute the microgrid supply by introducing harmonics, if international industry standards are not followed in design. Therefore, well designed conversion systems should be deployed to limit the harmonic level in the system. In different operating conditions, these inverters can also inject inter-harmonics with possible flicker impact [45]. According to IEC technical report [46], the testing of PV inverters should be executed by adjusting their power outputs at $25 \%, 50 \%$, and $100 \%$ of rated power to analyse the harmonics emission in the system.

For microgrids, anti-islanding protection should be considered to accommodate microgrid operations and the transition between on-grid to off-grid operations. According to IEEE 9292000, IEEE 1547.1, VDE 0126.1.1 and IEC 62116, the converters should have the capability to detect the fault/ islanding and then disconnect microgrid from the main grid within specific time interval [47]. In [48], a non-isolated single stage three-port converter is proposed to improve the conversion efficiency of storage systems, used for microgrid applications.

Apart from power electronics, optimal and controlled operation of microgrid is required. These operations can be divided into two categories: technical and economic. The objective of all economical controls is to minimize the operating cost of community systems. Whereas, technical controllers ensure the microgrid security and stability which becomes crucial in offgrid mode, e.g., voltage and frequency controls. In literature various design and operational management models have been proposed to maximize microgrid benefits. In [49], the basic structure of the multi-microgrids is analysed by many aspects which can include voltagegrade classification, phase-sequence and AC-DC constitutional forms. Haddadian et al. [50], proposed a multi-microgrid approach for optimal operation of active distribution networks and then a non-dominated genetic algorithm-II is used to solve the multiobjective optimisation problem. The microgrid operation and regulatory challenges faced in Singapore are investigated in [51]. In [52], a conventional controller is adopted to investigate the stability of single-phase community microgrids in islanding mode which is based on sensitivities of DERs and design of controllers and converters.

In [53], a two-level hierarchical hybrid control scheme is proposed for microgrids in which upper level discrete management scheme is ensuring the system stability and security of microgrid while lower level schemes are accountable for dynamic performance regulation. A very similar work based on hierarchical and distributed control schemes for microgrids is presented in [54]. In [55], a community microgrid test-bed, based on hardware-in-loop (HIL) controller is proposed for dynamic validation. Wang et al. [56], a voltage sensitivitybased decentralised approach is proposed to provide the voltage related ancillary services in active distribution networks comprised of multi-microgrids. A Lyapunov and queueing theory based energy management system is designed in [57] for community microgrid with renewables and EV battery swapping stations.

A hierarchical coordination scheme is proposed in [58] with primary, secondary, and tertiary controls to optimize the economic operations in community microgrids comprised of multiple ac-dc microgrids. A harmony search based dynamic economic dispatch of micro- 
grids, considering multiple scheduling strategies, is presented in [59]. A two-stage aggregated control is proposed in [60] to allow P2P energy sharing with one way communication. Madiba et al. [61] presents an intelligent control method to solve the load-shedding problems of microgrids which effectively reduces the operating time of diesel generator. In [33], a decision tree based optimal planning of BESSs along with energy balancing control algorithm is proposed for planned community microgrids. Sameti et al. [62], present an optimal design and operation concept of net-zero district by integrating BESS. An energy storage control algorithm is proposed in [63] for residential community microgrids aiming to reduce the operating cost of the system. A multi-agent based economic dispatch of community microgrids is proposed in [64] where, each agent is capable to participate in retail energy markets for trading.

The optimisation frameworks and techniques play an important role in determining optimal solution of microgrid design and management problems [65]. The optimization techniques can help to design high energy efficient systems with minimum cost and required infrastructures [66]. In literature, various optimisation methods and frameworks have been developed to solve microgrid design and dispatch problems. Su et al. [67], proposed a contract-based energy block-chain framework for optimal EV charging in smart communities. A multi-agent based demand response program is proposed in [68] to optimize independent decision makings of utility and communities to reach Nash equilibrium. An quantumbehaved particle swarm optimisation (PSO) based day-ahead scheduling, by improving the rigid coupling between power grid and heating networks, for integrated community energy systems is proposed in [69]. A very similar day-ahead scheduling strategy is proposed in [56] by considering the effect of multiple thermal energy storage devices. A MIP based scheduling of community microgrids is presented in [70]. In [71], mixed-integer linear programming based hybrid solar and heat driven district cooling system design and operation schemes are presented. A hybrid PSO technique is adopted in [72] to solve the optimal economic operation of community microgrids. In [59], a harmony search algorithm is adopted to solve dynamic economic dispatch of microgrids. A P2P optimisation model is developed in [73] to allow the participation of PV and BESS in microgrid energy market.

\subsection{Smart energy management and demand response}

This feature facilitates the microgrids to monitor and control the power generation and load demand in real-time. It also helps to curtail/store the excess renewable power generation or demand during off-grid operations of microgrids. The demand response (DR) can play an important role in effective utilization of community energy. In commercial and industrial communities, DR can help to reduce the energy consumptions up to some extent.

In [70], hourly optimal load scheduling is presented to minimize the electricity payment of community microgrid. Hu et al. [72] have optimised the time series output of temperature controlling devices to control the load demand of community microgrids. A droop characteristics based energy management system is proposed in [74] to minimize the operating cost of off-grid microgrids in remote communities. An energy reciprocity concept is investigated in [75] to demonstrate the buildings' heating, cooling, and power sharing abilities to minimise 
design and operating cost of their energy systems. Noor at al. [76], a game theory based demand response is proposed by incorporating storage components and blockchain technology for efficient operations of microgrid. A game-theory based market model is developed in [77] to sell the stored energy in batteries by participating in demand response. A very similar game-theory based energy trading mechanism is developed in [78] for P2P energy sharing in microgrids. In [79], an energy management system based on intelligent load control, by considering the thermal dynamic model of community houses, is developed.

\subsection{Retail energy markets}

The increasing possibilities of revenue generation from community microgrids, beyond reliability and resiliency, is contributing to the rise of third-party and mixed-ownership models in distribution systems. The electricity regulators from all across the globe are promoting the mixed models while ensuring that the electricity retail market works in the interests of consumers [80]. In the future, the annually increasing electricity demand including EVs may be constrained by traditionally designed distribution networks. These system will require substantial upgrade to accommodate growing EV penetration. The peer-to-peer (P2P) energy sharing/trading in microgrids can alleviate the reliance on existing network infrastructure and potentially save millions by postponing system reinforcement.

In literature, various retail energy market models have been suggested for distribution systems. In [81], some energy prosumers based business models are developed. To optimize the local energy generation among consumers, some P2P energy trading models are also suggested in $[82,83,84]$. A P2P energy retail market model is proposed in [85] for hierarchical community microgrids to promote regional energy trading. In [86], a multi-agent system information based synergistic platform structure is proposed for community energy system planning to improve the participation of multiple proprietors. A very similar multi-agent based P2P energy sharing framework is developed in [87].

Chao et al. [60], proposed a P2P energy sharing mechanism in which each prosumer is allowed to share energy through third-party intervention. Patel et al. [88], have proposed a multi-agent-based forecasting method for enhancing the profit of single and multiple ownership microgrids by minimizing the forecasting errors of intermittent generators. For effective operations and to develop a competitive energy market of multi-party community microgrids, an iterative bi-level business model is proposed in [89]. A blockchain-based P2P energy market is developed in [90] for energy trading between prosumers and consumers in community microgrids and evaluated on Brooklyn microgrid.

In discussed literature, various design and operational management models have been proposed, assuming that initial investments are done either by utilities/consumer or sometimes third parties. However, a combined business model of community microgrid in retail energy market, comprised of multiple investors and stakeholders facilitating time of use (ToU), feed-in tariff (FIT), and fixed price (FP), has to be investigated. The weak interaction between different stockholders at planning and operational management makes the community energy system model less efficient. Therefore, optimal design of community microgrid along with techno-economic energy management has been investigated in this work. 
In this paper, a new two-stage optimisation framework is developed for optimal design (sizing) and operational energy management of urban and remote community microgrids. To alleviate some of the economic barriers, in the proliferation of prosumers, due to high initial investment and management costs of DERs, a third-party investment based planning framework is developed in stage-1. In this model, DERs are deployed and managed by different stakeholders such as roof-top solar panels (RSPs), BESSs, and micro diesel engine (MDE). In stage-2, a combined P2P retail energy market model is developed by considering ToU, FITs and FPs. In this open market model of community, each customer would have an opportunity of cost-effective and reliable supplier selection in real-time, unlike current offline decision making in the UK. A new energy management scheme is also proposed to minimise the daily operating cost of the community. An improved variant of the genetic algorithm (GA) is used to optimise decision variables in both stages. Different case studies are framed and investigated to demonstrate the potential of the proposed model to design urban and remote community microgrids. The case study shows that the proposed model minimizes the daily operating cost of urban and remote community systems effectively while maximizing the benefits of investors.

\section{Proposed Optimisation Framework for Third-party Investment and Retail Energy Market in Community Microgrids}

In the existing deregulated environment of modern power systems, the direct involvement of energy consumers is rather limited due to techno-economic barriers. Generally, distribution network operators (DNO's) are the primary energy distributors, and tend to have monopoly, in their area of energy distribution. In this scenario, most end users have no sight on the actual DUoS and incurred costs are not reflected in electricity bills. Although, these price controls are reviewed by energy regulators and set for certain period of time, e.g., 8 years in UK. The Office of gas and electricity market (Ofgem), UK is facilitating the openness of retail electricity markets by introducing fair competitions [80]. It also ensures the transparency of information to all individuals in which customer can switch to any energy supplier as per the individuals' requirements and costs. In these market models, the suppliers compete on energy prices and services with a pressure to maintain low price as high energy price can have risk of losing customers. The regulator has rights to monitor and take action against anti-competitive activities to guarantee fair competitions in these markets.

The proposed third-party based DER investment, energy management, retail energy market models are formulated and solved in two-stages. In stage-1, the optimal sizing of different DERs are determined by considering the grid connected and islanding operations of microgrids. The optimal operational management of designed microgrid is performed in stage-2, aiming to minimise daily operating cost of microgrid under proposed P2P energy trading, energy management system (EMS), and schemes. The proposed two-stage optimisation problem is formulated in following sections. 


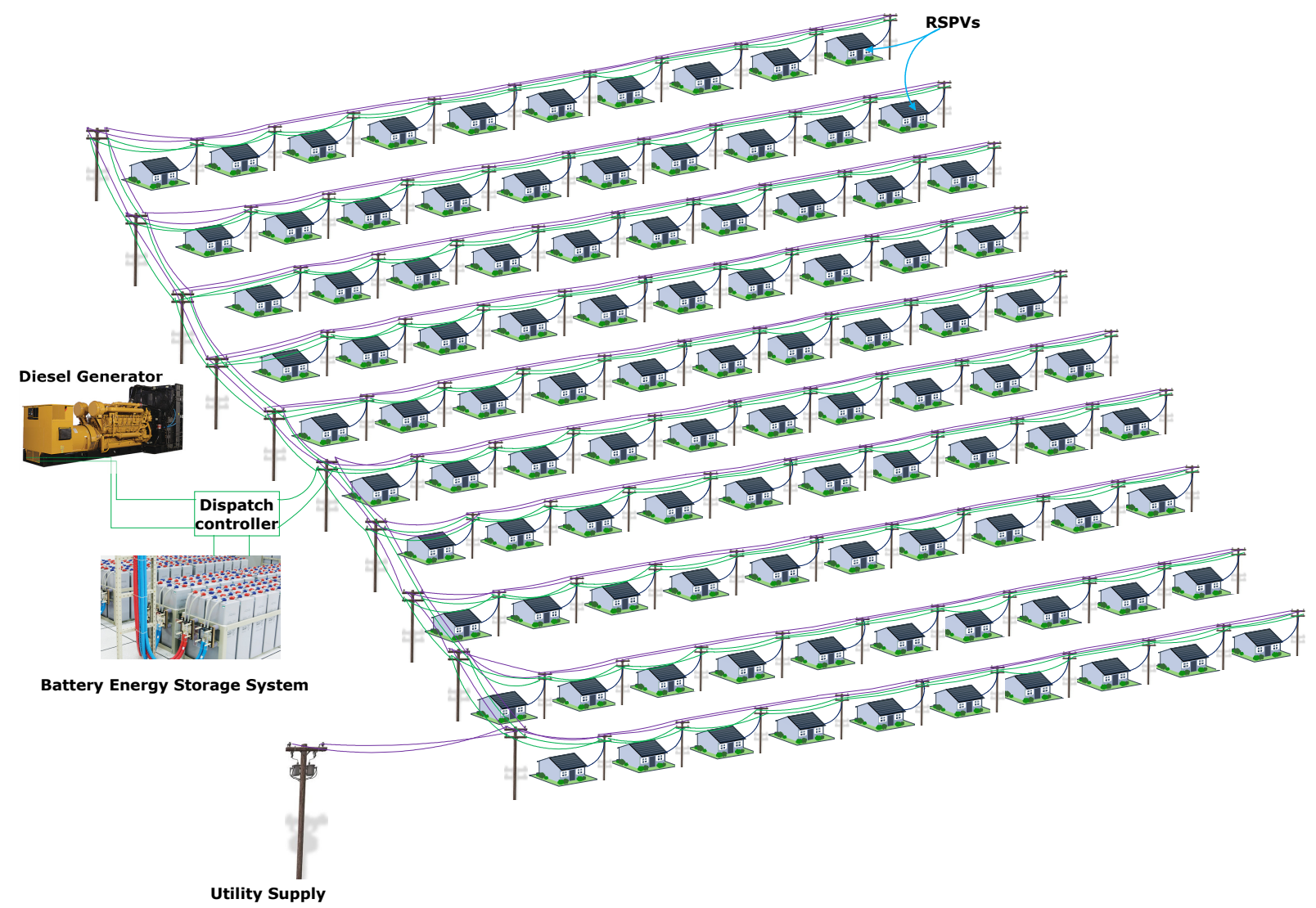

Figure 1: Prototype of proposed community microgrid with multiple distributed energy resources

\subsection{Stage-1: Proposed third-party investment based optimal design of community micro- grids}

The UK is on the way to subsidy free renewables by 2020. In-spite of various subsidies on renewable energy resources in previous years, many consumers have not installed roof-top solar PV due to high initial capital investment and costs for regular maintenance. In order to overcome some of the issues, Ofgem allowed third-party investments and encouraging retail energy market models in distribution systems. In the proposed model, some of the ongoing policies of Ofgem, UK are adopted to attract third-party investments [91], to proliferate grid connected and off-grid community microgrids.

In this stage, a regulated third-party based microgrid design/planning problem is formulated in which multiple stakeholders are allowed to participate in community based retail electricity markets by investing in different DERs such as RSPs, MDE and BESSs. Under this proposed scheme, all types of DER investments are done by third-parties only. The DNO and customers are not sharing any type of investment costs. However, the community customers are allowing investors to deploy SPVs on their roofs under a long-term bi-lateral contract with FITs. A prototype of the proposed model is shown in Fig. 1.

To determine the optimal sizing of DERs in community systems, a new objective func- 
tion is formulated by combining multiple objectives. A penalty function based approach is adopted to combined multiple objectives into single objective and expressed as

$$
\min F_{\text {design }}=\left[\sum_{t=1}^{T} F_{\text {oprn }}(t) \cdot\left(1+R_{\text {curt }}^{r s p}(t)\right) \cdot\left(1+R_{\text {curt }}^{d}(t)\right)\right] \cdot\left(1+\Delta W_{B}\right)
$$

where,

$$
\Delta W_{B}=\left|\sum_{t=1}^{T} p_{\text {bess }}(t)\right|
$$

$F_{\text {oprn }}$ represents the operating cost of microgrid for time $t$, as expressed in (6). Equation (2) expresses the charging-discharging balancing of BESS over the time duration of $T$ which restores the state-of-charge (SOC) of BESS to its original level, towards the end of day. Here, $R_{\text {curt }}^{r s p}(t), R_{\text {curt }}^{d}(t)$, and $p_{\text {bess }}(t)$ denote the rate of RSP power curtailment, rate of load power curtailment, and BESS power dispatch at time $t$, all in $\mathrm{kW}$. The objective function (1) is adequately designed to accommodate the optimal sizing of RSP, BESS, and MDE. In this objective, $R_{\text {curt }}^{r s p}(t)$ is considered as the penalty function to minimise over-sized RSP system while simultaneously maximising BESS charging capacity. Similarly, $R_{\text {curt }}^{d}(t)$ is another penalty function that will help in maximisation of RSP and MDE penetration, facilitating BESS discharging, and minimisation of load curtailment. For ideal microgrid design, $R_{\text {curt }}^{r s p}(t)=R_{\text {curt }}^{d}(t)=0 \quad \forall t$.

The objective function expressed in (1) is subjected to following sizing constraints:

$$
\begin{gathered}
0 \leq p_{r s p}^{r a t} \leq p_{\text {rsp }}^{\text {Max }} \\
0 \leq w_{\text {bess }}^{\text {rat }} \leq w_{\text {bess }}^{\text {Max }} \\
0 \leq p_{\text {mde }}^{\text {rat }} \leq p_{\text {mde }}^{\text {Max }}
\end{gathered}
$$

here, $p_{r s p}^{r a t}, w_{\text {bess }}^{r a t}$, and $p_{m d e}^{r a t}$ are the optimisation variables to determine optimal rated sizing of RSP, BESS, and MDE respectively. Further, $p_{r s p}^{M a x}, w_{\text {bess }}^{M a x}$, and $p_{m d e}^{M a x}$ denote the maximum specified sizes of RSP, BESS, and MDE respectively.

\subsection{Stage-2: Proposed optimal energy management of community microgrids}

In this stage, DER owners will participate in real-time retail energy markets. The DER owners and grid are selling energy to the community under one of the tariff structures among ToU, FITs and FPs. The community microgrid is considered to be a single entity in the main grid. In stage-2, the optimal energy dispatch problem is formulated for designed community microgrids in stage-1. The optimal dispatch of different DERs is performed under proposed P2P energy trading and management schemes, discussed in following sections. The objective 
of this optimisation stage is to minimize the hourly operating cost of residential urban and remote community microgrids, expressed as

$$
\min F_{\text {oprn }}(t)=\alpha(t) \cdot C_{\text {grid }}(t)+\beta(t) \cdot C_{\text {der }}(t) \quad \forall t
$$

were, $C_{\text {grid }}(t)$, and $C_{d e r}(t)$ are representing the cost of power purchase from utility grid and DER, including RSP, BESS and MDE, at time $t . \alpha(t)$ and $\beta(t)$ are the binary decision variables of grid presence or grid-connected microgrid and resources integrations to microgrid respectively at time $t$. The cost of power purchase from these resources at time $t$, is defined as

$$
C_{\text {der }}(t)=\gamma(t) \cdot C_{r s p}(t)+\xi(t) \cdot C_{\text {bess }}(t)+\chi(t) \cdot C_{m d e}(t) \quad \forall t
$$

here, $C_{r s p}(t), C_{\text {bess }}(t)$, and $C_{m d e}(t)$ are representing the cost of energy purchase from RSP, BESS, and MDE respectively. Similarly, $\gamma(t), \xi(t)$, and $\chi(t)$ are the binary decision variables of RSP, BESS, and MDE to be connected with or present in local network or participating in retail energy market respectively.

The objective function expressed in (6) is subjected to following constraints:

$$
\begin{gathered}
p_{\text {grid }}(t)=\sum_{i=1}^{n_{H}} p_{i}^{d}(t)-p_{\text {rsp }}(t)+p_{\text {bess }}(t)-p_{\text {mde }}(t)-p_{\text {curt }}^{d} \quad \forall t \\
0 \leq p_{\text {mde }}(t) \leq p_{\text {mde }}^{\text {rat }} \quad \forall t \\
p_{\text {bess }}^{\text {disch }}(t) \leq p_{\text {bess }}(t) \leq p_{\text {bess }}^{\text {ch }}(t) \quad \forall t \\
\underline{E} \leq E(t) \leq \bar{E} \quad \forall t \\
E(t)=E(t-1)+p_{\text {bess }}(t) \quad \forall t
\end{gathered}
$$

Equations (8)-(12) are expressing the power balance, diesel generator limits, BESS charging/ discharging limits, SOC limits, and SOC balance constraints respectively. Further, $p_{i}^{d}(t)$, $p_{\text {rsp }}(t), p_{\text {mde }}(t), p_{\text {bess }}(t), p_{\text {bess }}^{\text {ch } / \text { disch }}(t)$, and $E(t)$ are denoting the power demand of $i$ th house, power dispatch of RSP, MDE, BESS, available power dispatch limits of BESS, all in kW, and available $\mathrm{SOC}$ in $\mathrm{kWh}$ at time $t$ respectively. The parameters $\underline{E}, \& \bar{E}$, and $n_{H}$, represent the minimum \& maximum specified SOC limits of BESS, and total number of houses in community respectively. Generally, the maximum and minimum SOC limits are considered as $\bar{E}=w_{\text {bess }}^{\text {rat }}$ and $\underline{E}=0.1 \times w_{\text {bess }}^{\text {rat }}[92]$

The cost of energy supplied by each DER is separately discussed in the following sections.

Cost of power purchase from main-grid: Traditionally, the utility grid is found to be the main source of power supply to the communities. The proposed residential community 
is also assumed to be fed by a common distribution transformer. The cost of power purchase from the grid is expressed as

$$
C_{\text {grid }}(t)=p_{\text {grid }}(t) \times e_{\text {grid }}(t)
$$

here, $p_{\text {grid }}(t)$ and $e_{\text {grid }}(t)$ are denoting the power supplied by main grid in $\mathrm{kW}$ and its price at time $t$ respectively.

Cost of power purchase from diesel generator: The diesel or gas generators are considered as one of the alternatives during power outages, in-spite of high emission and running costs. However, it requires a small space and cost of installation with high ramp rate. In remote communities, this is considered as main source of power supply. Therefore, one MDE is also considered in the proposed model and its running cost is expressed as

$$
C_{d e}(t)=\left(a_{0} \cdot p_{m d e}^{r a t}+a_{1} \cdot p_{m d e}(t)\right) \times e_{m d e}
$$

where, $a_{0}, a_{1}$, and $e_{m d e}$ are the intercept coefficient of fuel curve (units $/ \mathrm{hr} / \mathrm{kW}$ ), slop of fuel curve (units $/ \mathrm{hr} / \mathrm{kW}$ ), and per-unit diesel price respectively. The fuel price is varying with the amount of power dispatch.

Cost of power purchase from roof-top solar photovoltaics: In proposed schemes, the RSPs are being installed on the rooftops under some agreements between house owner(s) and investors. A long-term FITs plans are adopted for RSPs, cheaper than the utility grids [93]. The power generation of RSPs are linearly varying with solar irradiation, i.e., $p_{r s p} \propto s$, if other factors are assumed to be constant [94]. The cost of power purchase from RSP is expressed as

$$
\begin{gathered}
C_{r s p}(t)=p_{r s p}(t) \times e_{r s p} \\
p_{r s p}(t)= \begin{cases}p_{r s p}^{r a t} & \text { if } s(t) \geq s_{r a t} \\
p_{r s p}^{r a t} \cdot \frac{s(t)}{s_{r a t}} & \text { if } s(t)<s_{r a t}\end{cases}
\end{gathered}
$$

here, $e_{r s p}, p_{r s p}^{r a t}, s(t), s_{\text {rat }}$ are the price of per unit power purchase from RSP, i.e. FIT, rated capacity of RSP in $\mathrm{kW}$, solar irradiation at time ' $t$ ' and rated solar irradiation of RSP respectively.

Cost of power purchase from battery energy storage systems: The large-scale integration of renewables is increasing the power fluctuation or imbalance problems in modern distribution systems. The recent advancements in storage technologies are proliferating the integration of BESS in distribution systems. It is adding an extra degree of flexibility to the systems by the way it charged and discharged as per the need of system operator. Nowadays, BESS is playing a vital role to minimise the power mismatches caused by variable nature of loads and renewables. However, the high investment cost and shorter lifetime are the limiting factors in large-scale integration of BESSs. 
The optimal deployments and energy management may generate enormous amount of benefits for utility, consumer, BESS owner [94]. In the proposed model, BESS is also assumed to be deployed by third-party in stage 1 and then participates in retail energy markets of community microgrids under FP contract subjected to SOC availability. The cost of power purchase from BESS is defined as

$$
C_{\text {bess }}(t)=p_{\text {bess }}(t) \times e_{\text {bess }}
$$

The optimal dispatch of BESS, $p_{\text {bess }}(t)$ is optimized between available charging, $p_{\text {bess }}^{c h}(t)$ and discharging, $p_{\text {bess }}^{\text {disc }}(t)$ limits at time $t$, as suggested by [92] and, expressed in (18) and (19) respectively.

$$
\begin{aligned}
& p_{\text {bess }}^{\text {ch }}(t)= \begin{cases}0 & \text { if } E(t-1)=\bar{E} \\
\overline{p_{\text {bess }}} & \text { if } E(t-1)+\eta_{\text {bess }} \overline{p_{\text {bess }}} \leq \bar{E} \\
\bar{E}-E(t-1) & \text { if } E(t-1)+\eta_{\text {bess }} \overline{p_{\text {bess }}}>\bar{E}\end{cases} \\
& p_{\text {bess }}^{\text {disch }}(t)= \begin{cases}0 & \text { if } E(t-1) \leq \underline{E} \\
-\underline{p_{\text {bess }}} & \text { if } E(t-1)-\frac{\underline{p_{\text {bess }}}}{\eta_{\text {bess }}} \geq \underline{E} \\
-(E(t-1)-\underline{E}) & \text { if } E(t-1)-\frac{\underline{p}_{\text {bess }}}{\eta_{\text {bess }}}<\underline{E}\end{cases}
\end{aligned}
$$

where, $e_{\text {bess }}(t), \overline{p_{\text {bess }}}$ and $p_{\text {bess }}$ is the cost of power purchase from BESS in $t$ th hour, maximum charging and discharging power limits of BESS or converter in an hour respectively. The optimal operational management of community microgrid is performed under the proposed P2P energy trading and EMS schemes, discussed in the following sections.

\subsubsection{Proposed P2P real-time energy trading}

Unlike, current offline energy supplier switching schemes in the UK, we have proposed a real-time supplier switching model under P2P energy sharing within consumer, producer, and prosumer (i.e., producer + consumer) of a community microgrid, shown in Fig. 2. Figure shows that there are mainly three parties in proposed P2P retail energy trading market: consumers, prosumers and the network operator. These parties generate profit by an effective utilisation of DUoS to share energy between peers. The smart home energy management system (SHEMS) assumed to be deployed in each house will provide the opportunity of real-time switchover to any supplier, in P2P retail energy market, as per the customer needs and economics. The SHEMSs are having access to real-time energy pricing information from different retail energy suppliers including the main grid. In this P2P energy trading model, the consumers are able to minimise their energy bills by DUoS. They also exchange information amongst themselves to participate in P2P energy trading in these retail electricity markets. The BESS owner have flexibility to charge the battery either from grid or RSPs based on energy availability and tariffs. The pseudo-code of proposed P2P electricity trading including SHEMS is presented in Algorithm 1.

\subsubsection{Proposed EMS for techno-economic operation of microgrid}

In this section, the proposed optimal operational energy management schemes of community microgrids are discussed. In this model, the regulators make sure that DERs should 


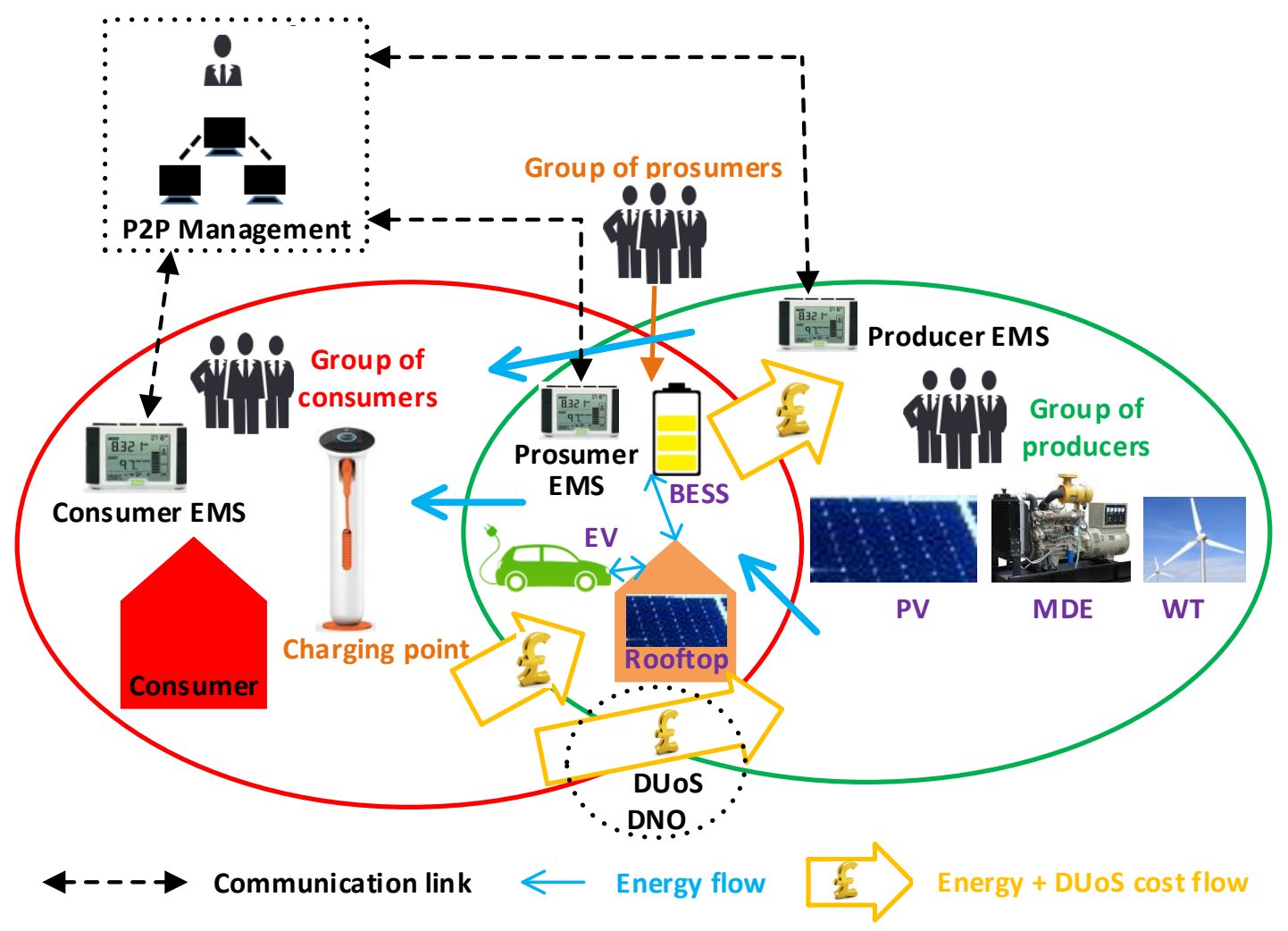

Figure 2: P2P energy trading between producer, consumer, and prosumer (producer + consumer) and DUoS

follow the regulatory guidelines in order to maintain the system stability and security. The following rules are designed in the proposed model:

a) The community microgrid is not allowed to feed power back to main grid. Therefore, excess power generation has to be stored, if any.

b) Real-time energy balance should be ensured to avoid stability issues; especially, when microgrid is operating in islanding mode.

c) In islanding mode, the critical load should be supplied first and then remaining power will be supplied to non-critical loads.

Based on these rules, the energy management system of proposed community microgrid is presented in Fig. 3. The proposed EMS scheme is utilised in stage 2 to perform the optimal economic operations of microgrid designed in stage 1 of proposed optimisation framework.

\section{Proposed Genetic Algorithm based Optimal Design and Management of Com- munity Microgrids}

The proposed two-stage microgrid design and scheduling problem is formulated as a mixed-integer, non-linear and non-convex optimisation problem. It is comprised of mixed variables such as binary decision and continuous power dispatch variables along with some non-linear objectives and constraints. In stage-1, the optimisation variables can include 


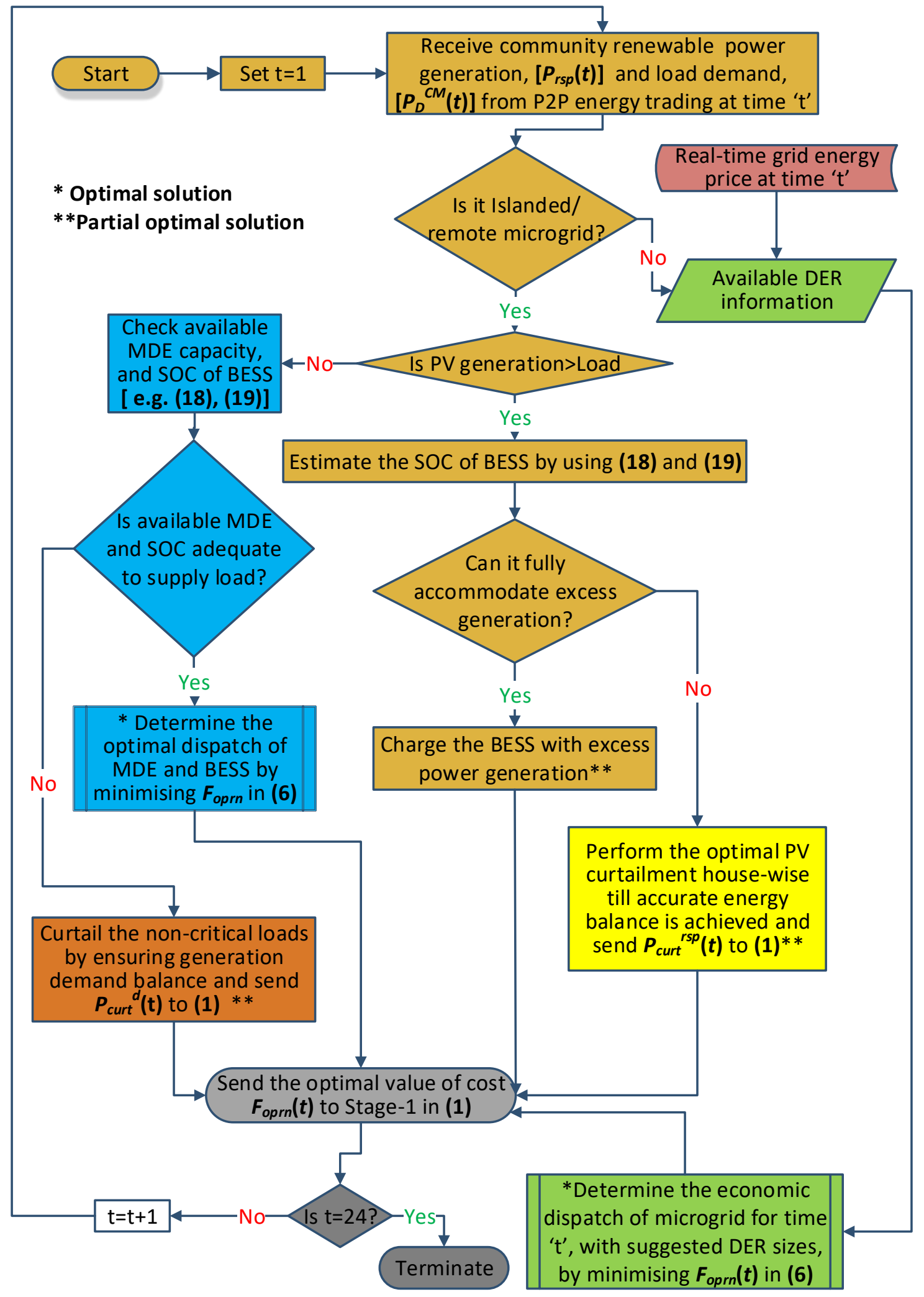

Figure 3: Proposed energy management system (EMS) and schemes for optimal operations of community microgrid 


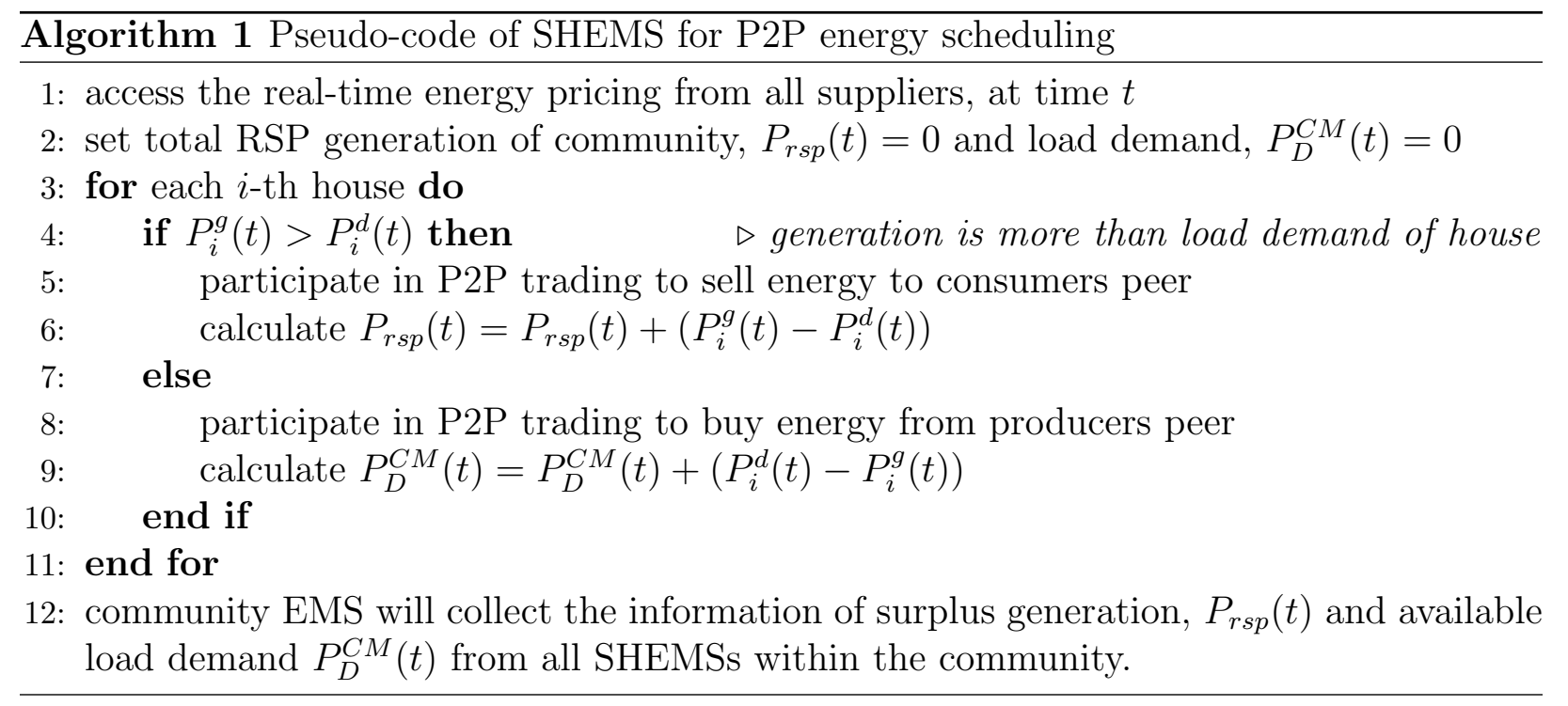

$p_{r s p}^{r a t}, p_{\text {bess }}^{\text {rat }}$, and $p_{\text {mde }}^{\text {rat }}$. Whereas, $\alpha(t), \beta(t), \gamma(t), \xi(t), \chi(t), p_{\text {bess }}(t), p_{\text {de }}(t)$, and $p_{\text {grid }}(t)$ are the optimisation variables of stage- 2 . To solve the proposed two-stage optimisation framework, developed in Section 2, an effective optimisation method is required. The metaheuristic methods are well-known for their ability to solve black-box optimisation problems, irrespective of the way of problem formulation. In both stages, an improved variant of genetic algorithm (GA) is adopted from [95]. However, the heuristic spark introduced in the reference is ignored. It is a derivative free population based stochastic optimisation technique. It has strong exploration ability to search the global optimal solution for real-life engineering optimisation problems [94]. The steps of adopted GAs are detailed below.

Step-i (Parameter setting): set the values of algorithm parameters such as crossover rate, $C_{R}$; mutation rate, $M_{R}$; maximum generation, $G_{\max }$, number of population, $n_{p}$ etc.

Step-ii (Initialisation): initialise the random but feasible population of individuals shown in Figs. 4 and 5 for stage- 1 and 2 respectively. It contains the optimisation variables of microgrid design or operation.

\begin{tabular}{||c||c||c||}
\hline$p_{r s p}^{r a t}$ & $p_{\text {bess }}^{\text {rat }}$ & $w_{\text {mde }}^{\text {rat }}$ \\
\hline
\end{tabular}

Figure 4: Structure of an individual (chromosome) adopted in stage-1

\begin{tabular}{||l||l||l||l||l||l||l||l||}
\hline$\alpha(t)$ & $\beta(t)$ & $\gamma(t)$ & $\xi(t)$ & $\chi(t)$ & $p_{\text {bess }}(t)$ & $p_{\text {mde }}(t)$ & $p_{\text {grid }}(t)$ \\
\hline
\end{tabular}

Figure 5: Structure of an individual (chromosome) adopted in stage-2 
Step-iii (Fitness calculation): calculate fitness values of $n_{p}$ individuals in the population, i.e., expressed in (1) and (6) for stage-1 \& 2 respectively.

Step-iv (Crossover): a modified two-point crossover is adopted from [95]. In each crossover, one parent is selected by roulette wheel selection and another is randomly.

Step-v (Fitness calculation): calculate fitness values of offspring generated in Step - iii. Retain two fittest individuals among these four individuals (i.e., offspring and parents) and discard remaining two.

Step-vi (mutation): to perform mutation, one element (gene) is selected from an individual and replaced with randomly generated element.

Step-vii (Fitness calculation): determine the fitness value of mutated individual and compare with original. Retain the fittest one.

Step-viii (Preserve the best individual): preserve the best individual with minimum cost.

Step-ix (Termination): Check whether all individuals have attained the same fitness value or maximum number of generation $G_{\max }$. If yes, move to Step-x otherwise return to Step-iv.

Step-x (Print results): print the best fitness value and corresponding individual.

The flowchart of improved GA-based approach is also shown in Fig. 6. The process-flow and objectives of both the stages are presented in Fig. 7. It also demonstrate the interaction of these stages at various levels.

\section{Case study}

To establish the applicability of proposed optimisation framework, for optimal design and operational management of community microgrids in retail energy markets, urban and remote community microgrids are designed. In this study, the demand profile of a residential community is considered. The fuel curve characteristic of MDE [96], and hourly load demand, solar power multiplying factor and energy pricing are shown in Fig. 8 [94]. The various parameters considered in this case study are presented in Table 2.

\subsection{Optimal design of grid accessible or urban community microgrids}

In this section, the optimal sizing of RSPs, BESS and MDE are determined for community system. The objective of this planning is to maximize the operational benefit of community systems. It includes the cost of daily energy operations by satisfying various techno-economic constraints. As discussed, third-party investment is encouraged in the community under a long-term contract. According to this, the DER owners will sell the power to community with predefined tariffs. Now, the optimal planning of DERs is performed under the proposed optimisation framework. In this microgrid design, the sizing of 


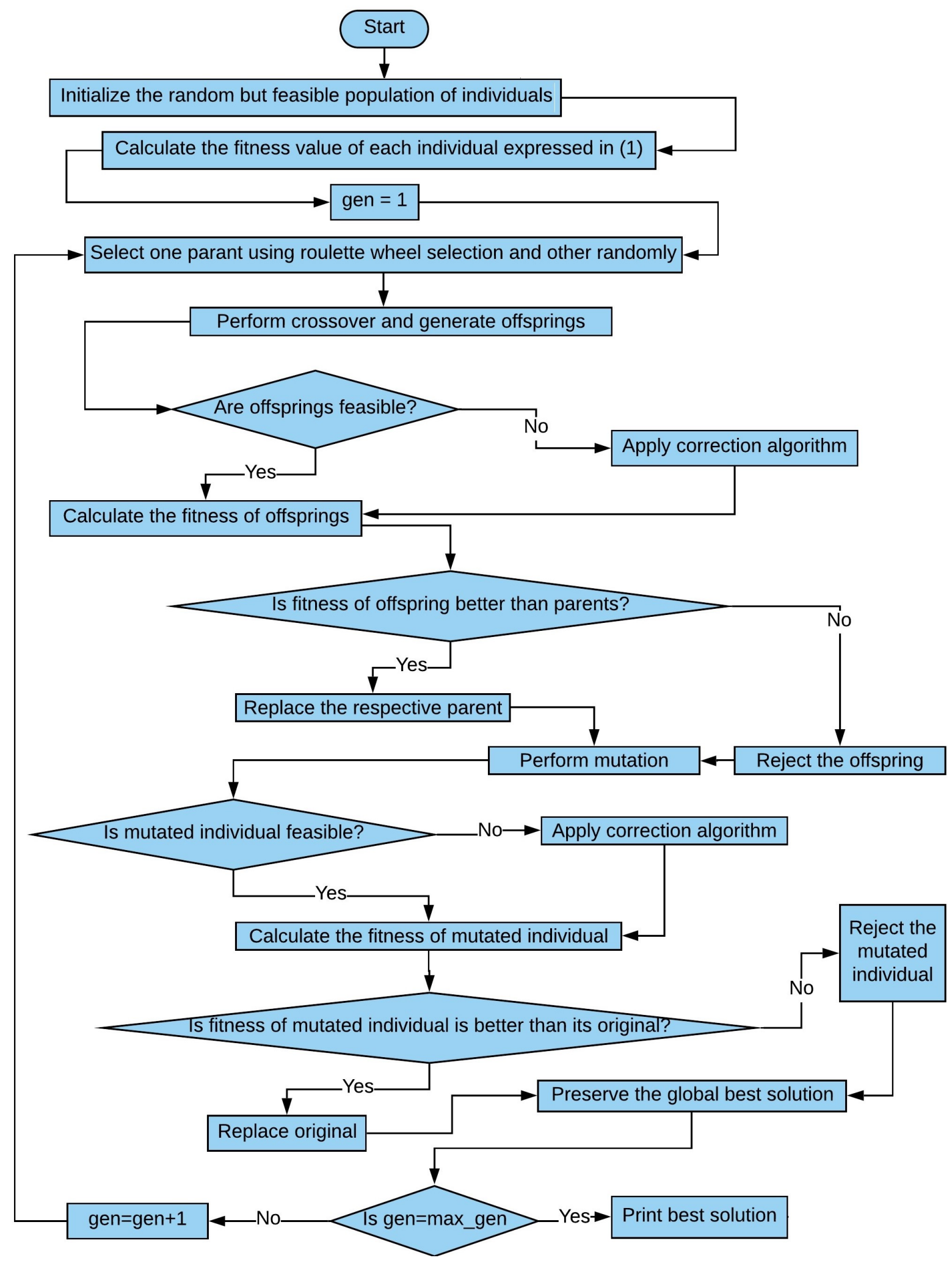

Figure 6: Flowchart of genetic algorithm used in both the stages 


\section{Stage-1 Optimisation for Optimal sizing of distributed energy resources}

Objective: Facilitate third-party based investment by optimal deployment of different DERs in urban and remote community energy systems.

Step-1: The optimisation variables of DER sizing are suggested by an individual of GA

Step-2: The Suggested DER sizes are send to Stage2 to analyse their cost minimisation ability of community system.

Step-3: Receive the corresponding optimised cost of community system for suggested DER sizes by an individual of GA.

Step-4: Repeat steps until the convergence criteria of $G A$ is achieved.

\section{Stage-2 Optimisation for hourly operating} cost minimisation

Objective: Supporting stage-1 to minimise the operating cost of community system, with suggested DER sizes, in each hour ' $t$ '.

Step-1: Receive the DER sizing information from Stage-1.

Step-2: Apply the P2P energy trading scheme to receive the information of consumers, producers and prosumers.

Step-3: Send this information to proposed EMS scheme.

Step-4: Receive the optimised cost of community system from EMS scheme.

Step-5: Send this optimised cost to corresponding GA individual in Stage-1.

Figure 7: Process flow of proposed two-stage optimisation framework based on GAs

Table 2: System parameter and data used in the case study

\begin{tabular}{lc}
\hline Name of parameter/constant & Value \\
\hline Peak demand or total sanctioned load of the community $(\mathrm{kW})$ & 690 \\
Critical Load $(\mathrm{kW})$ & 100 \\
Diesel price $(£ / \mathrm{L})$ & 1.20 \\
Intercept coefficient of fuel curve of $100 \mathrm{~kW} \mathrm{MDE}, a_{0}(\mathrm{~L} / \mathrm{hr} / \mathrm{kW})[96]$ & 0.032 \\
Slop of fuel curve of $100 \mathrm{~kW}$ MDE, $a_{1}(\mathrm{~L} / \mathrm{hr} / \mathrm{kW})[96]$ & 0.242 \\
Intercept coefficient of fuel curve of $730.77 \mathrm{~kW} \mathrm{MDE}, a_{0}(\mathrm{~L} / \mathrm{hr} / \mathrm{kW})[96]$ & 0.012 \\
Slop of fuel curve of $730.77 \mathrm{~kW} \mathrm{MDE}, a_{1}(\mathrm{~L} / \mathrm{hr} / \mathrm{kW})[96]$ & 0.249 \\
Rated capacity of MDE, $p_{m d e}^{\text {rat }}(\mathrm{kW})[96]$ & 100 \\
Diesel density in UK, $\rho_{\text {fuel }}(\mathrm{g} / \mathrm{L})$ & 832 \\
Average net lower heating value of the diesel, $L H V_{\text {fuel }}(\mathrm{MJ} / \mathrm{kg})$ & 42.6 \\
FIT for RSPs, $e_{r s p}(\mathrm{p} / \mathrm{kWh})$ & 3.93 \\
Energy selling price by BESS, $e_{\text {bess }}(\mathrm{p} / \mathrm{kWh})$ & 10.30 \\
Max. charging/discharging of BESS at any $t, \overline{p_{\text {bess }}} / \underline{p_{\text {bess }}}(\mathrm{kW})$ & 450 \\
\hline
\end{tabular}




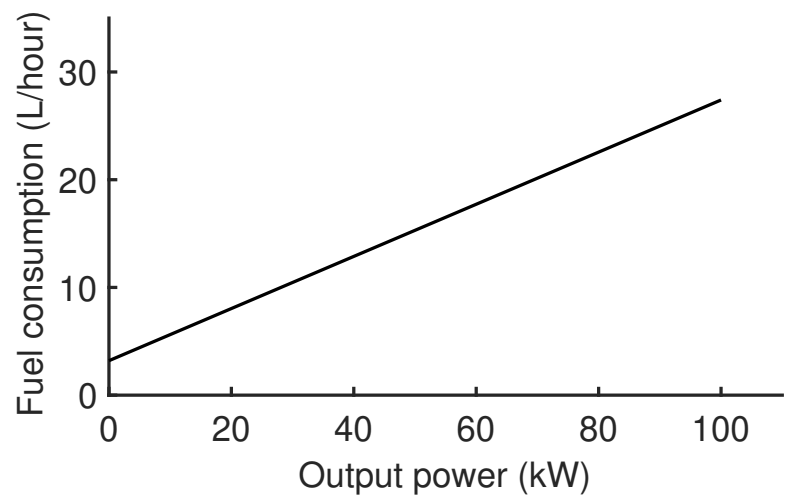

(a)

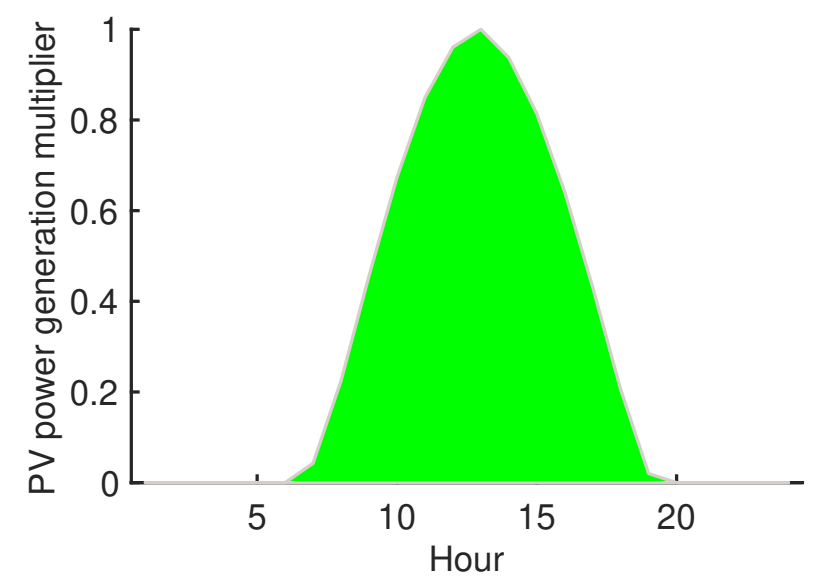

(c)

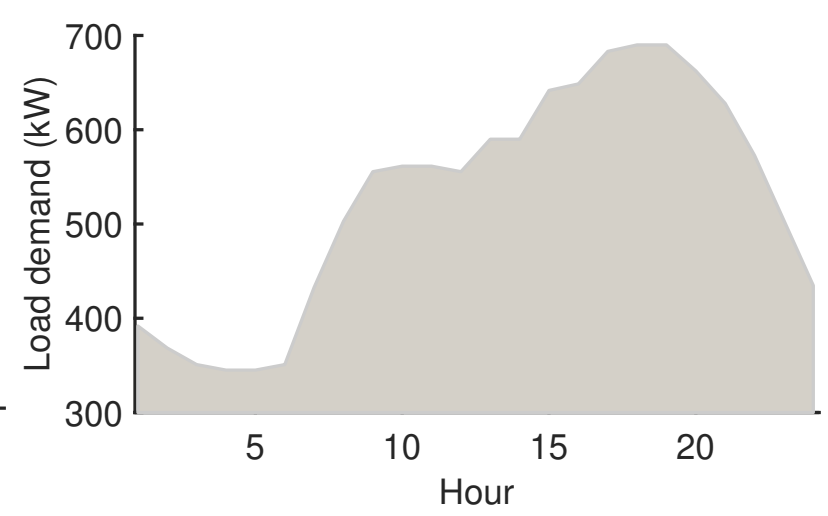

(b)

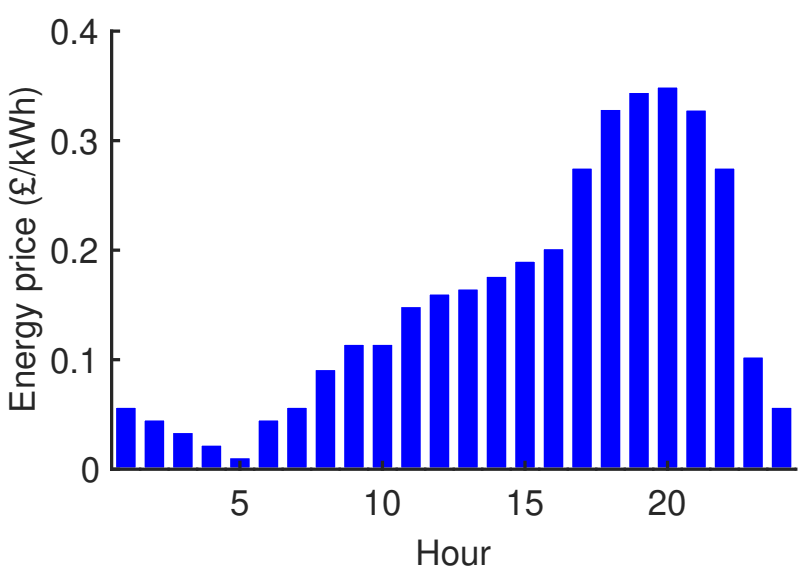

(d)

Figure 8: Case study data: (a) Fuel characteristic of 100kW MDE, and hourly (b) load demand (c) RSP power generation multiplying factor $(d)$ energy price

these resources is determined by minimising the objective function, expressed in (1). Therefore, the maximum penetration of RSPs will be limited by the load demand and storage capability.

According to the definition, microgrid should have ability to operate in islanding mode if grid fails. To design a compromising microgrid system, the optimal sizing of these resources are determined by analysing following cases

- Case-I: Base case, no DER

- Case-II: Grid connected operation of microgrid

- Case-III: Islanding operation of microgrid.

These cases are assumed to be the most likely scenarios in microgrid operations. The proposed optimisation framework developed in Section 2 and GA presented in Section 3 are adopted to design a compromising community microgrids by considering these cases. The 
Table 3: Daily estimated revenue potential of each stakeholder and community profit

\begin{tabular}{lcccc}
\hline \multirow{2}{*}{ Owner $(\mathrm{s})$} & & \multicolumn{2}{c}{ Optimal design of microgrid } \\
\cline { 3 - 5 } & $\begin{array}{c}\text { Revenue } \\
\text { potential }(£) \\
\text { Case-I }\end{array}$ & $\begin{array}{c}\text { Optimal size } \\
(\mathrm{kW} / \mathrm{kWh})\end{array}$ & Revenue potential $(£)$ \\
\hline Utility & 2236.06 & - & 1314.32 & 1120.44 \\
MDE & - & 100 & 208.90 & 241.43 \\
RSPs & - & 575 & 163.96 & 163.96 \\
BESS & - & 2500 & 235.15 & 313.32 \\
\hline Estimated consumer profit $(£)$ & - & & 313.71 & $396.91^{*}$ \\
\hline Energy not supplied $(\mathrm{kWh})$ & 0 & - & 0 & 155 \\
\hline *PEO -Partial economic operations & & & & Case-III \\
\hline
\end{tabular}

optimal sizes of RSP, BESS, MDE and revenue generation potential of each stakeholder, determined under the proposed optimisation framework is presented in Table 3.

To demonstrate the techno-economic potential and operational flexibility of designed microgrid, optimal dispatch is determined for these cases individually by using Stage-2 optimisation only. These cases have been discussed in the following sections.

\subsubsection{Case-I: Base case, no DER $[\alpha(t)=1 \& \beta=0 \forall t]$}

In case-I, the community load is completely supplied by utility grid, the only stakeholder and energy supplier, as in conventional model. This case is framed to determine the cost of community energy consumption when power is purchased from main grid without any benefit of distribution use of system (DUoS). Further, no DER is assumed to be present in community system. The daily operating cost of community load is determined for this case and presented in Table 3.

\subsubsection{Case-II: Grid connected operation of microgrid}

In case-II, multiple stakeholders are allowed to participate in retail energy markets by considering techno-economic constraints of the system. The main grid provides TOU tariff therefore DER owners can optimize their resources dispatch to maximise operational benefits, and to make investment profitable through proposed EMS. At the same time, community customers (both consumers and prosumers) are benefited by DUoS and have opportunity to change their energy suppliers in real-time through P2P energy trading.

The optimal revenue generation potential of each stakeholder is shown in Table 3. It shows that all stakeholders are able to generate the revenue from designed community microgrid in grid connected operation. The operational flexibility of the system, under high penetration of RSPs, is enhanced by BESS, as shown in Fig. 9. It has been observed that the battery owner charges the BESS either in light load hours or high PV generation. The 
BESS remains in idle mode during 8:00 to 15:00 hours approximately. Due to high running charges, community purchases MDE power in peak load hours only, i.e., 18:00 to 21:00. As observed from (14), the MDE requires a minimum running charges of $a_{0} \cdot p_{d e}^{r a t} \times e_{d e}=3.84 £$, even at zero power generation in each hour. The MDE's electrical energy calculated at rated generation is found to be $n_{d e}=37.07 \%$ though, the alternator efficiency is $=92.5 \%$.

In this model, the consumers are allowed to participate in $\mathrm{P} 2 \mathrm{P}$ retail electricity market by changing their energy supplier or prosumer in real-time, with the help of P2P SHEMS. In this model, the excess energy generation from neighbouring prosumers with RSP (Peer 1) are directly selling into their neighbourhood (peer 2), as discussed in Section 2.2.1. In this $\mathrm{P} 2 \mathrm{P}$ retail market, the community has been generated the profit by minimizing their energy bills.

\subsubsection{Case-III: Optimal operation in islanding mode}

To demonstrate the ability of designed microgrid to operate in islanding mode, a grid failure scenario is investigated in this case. To simulate this, a severe grid failure situation is considered. For example, grid fails during peak load hours between 11:00 to 19:00 hours. By considering this severe situation, the microgrid optimisation model proposed in stage-2 is applied and simulation results have been presented in Table 3. The table shows that the revenue generation of RSPs remains the same but increased for BESS and MDE owners. The revenue of BESS owner is the highest, due to the maximum flexibility potential of BESS.

It is found that the energy management system, shown in Fig. 3, is successfully managed the islanding operation for 10 hours, in peak load condition. However, some amount of load has been curtailed by EMS, i.e. $155 \mathrm{kWh}(25 \mathrm{~kW}$ and $130 \mathrm{~kW}$ at 18:00th and 19:00th hours respectively), which is slightly more than the shiftable load of the system (i.e., $20 \%$ of peak load). In this operation, the DERs are supplied the critical as well as a large amount of non-critical loads of the community.

Figure 10 shows the optimal dispatch of BESS, main grid, RSPs, and MDE for Case-III. It shows that maximum load of the community is supplied by BESS during islanding mode which has been charged in light load hours. Whereas, the maximum capacity of MDE has been utilized when BESS reaches to minimum SOC level. Fig. 10(a) shows that BESS remains in idle mode during 10:00 to 18:00 hours but not fully charged.

\subsection{Optimal design of off-grid microgrids for remote communities}

As discussed earlier, the remote communities have limited or even no access to utility grid thus majorly dependent on diesel generators. In order to design a remote community microgrids, the following cases are simulated and compared to demonstrate the revenue generation potential.

- Case-I: Conventional MDE based community power supply

- Case-II: Proposed remote community microgrid.

The proposed optimisation framework is used to design the remote community microgrid. The optimal sizing of RSPs, MDE and BESS is presented in Table 4. These cases are presented in the following sections. 


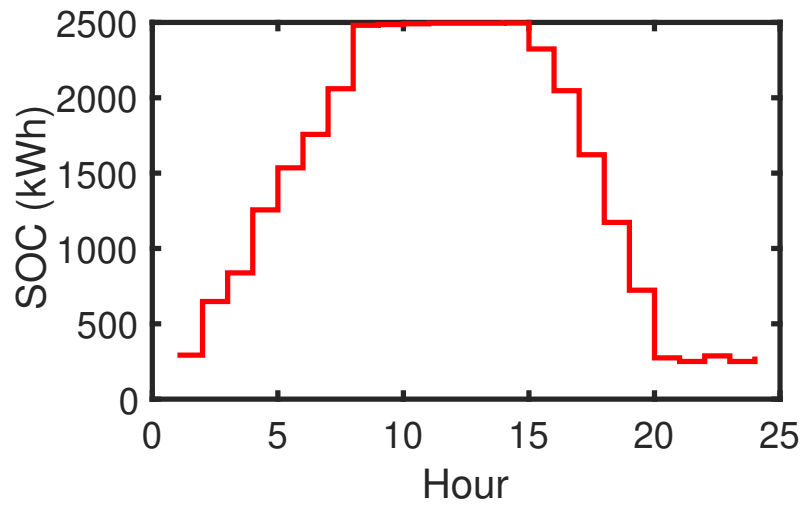

(a)

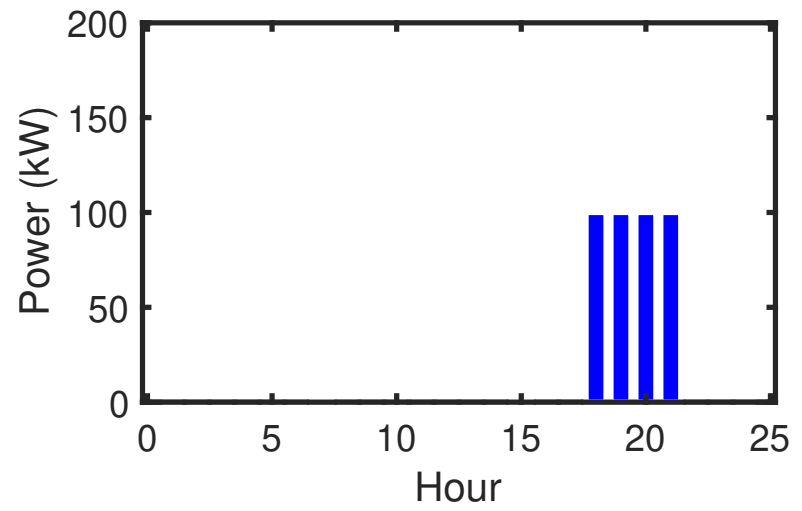

(b)

Figure 9: Optimal DER dispatch in grid connected mode: (a) SOC of BESS, (b) MDE power

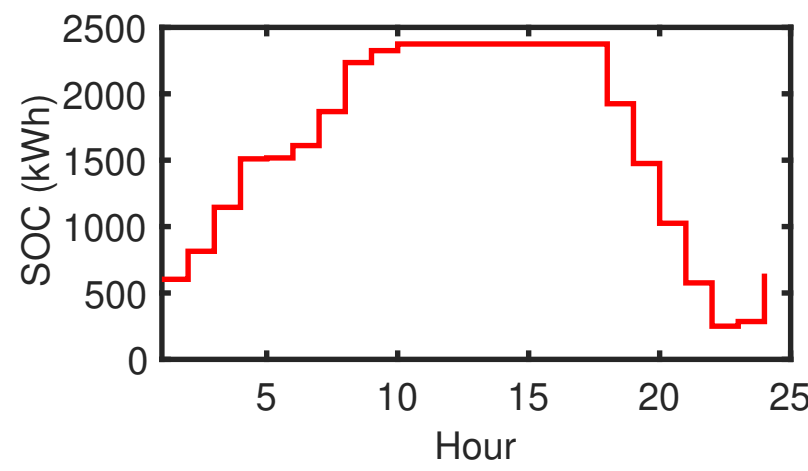

(a)

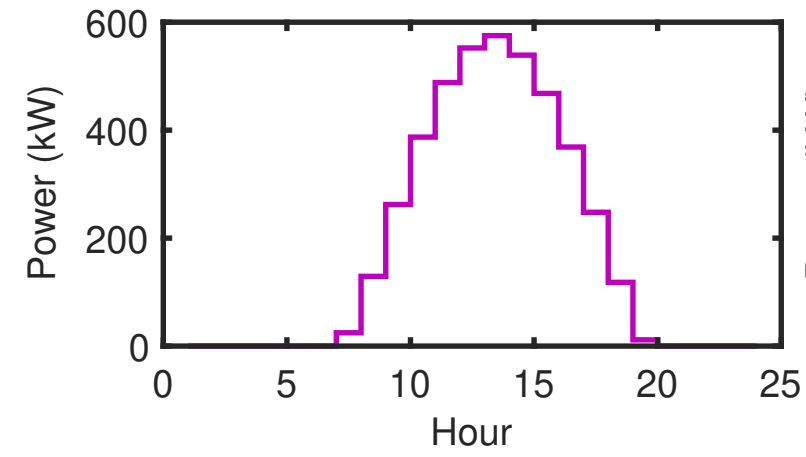

(c)

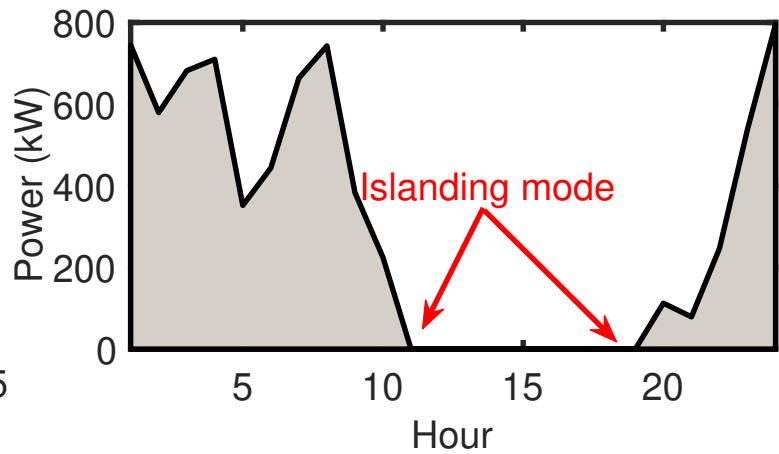

(b)

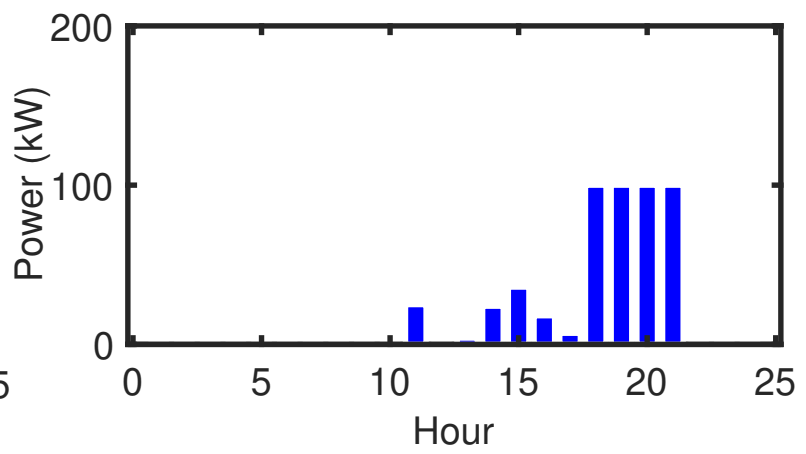

(d)

Figure 10: Optimal dispatch of different DERs in islanding mode: (a) SOC of BESS, (b) utility supply, (c) RSP generation, and (d) MDE power

\subsubsection{Case-I: Conventional MDE based community power supply}

To simulate this scenario, we have considered a diesel generator designed by 'Diesel Generator UK'. The model is 'GSW 1000M Pramac MTU Open Generator 913kVA'. The prime 
Table 4: Daily revenue generation potential of each stakeholder and profit of remote community

\begin{tabular}{lccc}
\hline & Case-I & \multicolumn{2}{c}{ Case-II } \\
\cline { 3 - 4 } Owner(s) & \begin{tabular}{c} 
Revenue \\
potential \\
\cline { 3 - 4 }
\end{tabular} & $\begin{array}{c}\text { Optimal size } \\
(£)\end{array}$ & $\begin{array}{c}\text { Revenue potential } \\
(\mathrm{kW} / \mathrm{kWh})\end{array}$ \\
\hline DE-based system & 4031.60 & 300 & 1251.67 \\
RSPs & - & 1025 & 292.28 \\
BESS & - & 2125 & 263.16 \\
\hline Estimated consumer profit $(£)$ & - & & 720 \\
\hline Energy not supplied $(\mathrm{kWh})$ & 0 & & \\
\hline *- Partial economic operations & & &
\end{tabular}

power rating of this generator is $730.77 \mathrm{~kW}^{1}$, which can supply full load of the community for all time [97]. The average power load of the community over 24 hours is $527.32 \mathrm{~kW}$, which is close to $70 \%$ capacity of this DE. The daily running cost of the community is presented in Table 4. It can be observed that the running cost of a conventional remote community system is almost double of grid assisted microgrid, calculated in the previous section.

\subsubsection{Case-II: Proposed remote community microgrid}

In this design, the optimal sizing of different DERs are determined to design a remote community microgrid. The sizing of RSPs are limited by zero PV curtailment. Whereas, the BESS sizes are limited by flexibility of load supply and reduce the load and RSP power curtailment, as presented in Fig. 3. Similarly, MDE sizing is also optimized by load demand curtailment of community, as expressed in (1). Table 4 shows the optimal sizing of different DERs deployed to supply the community load.

The simulation results reveal the large potential of open-market community microgrid for remote areas which can attract the investors to invest in such projects. In the absence of grid, the communities completely rely on local energy resources. It is also observed that some of the load has been shed during these operations which are assumed to be flexible loads, less than $20 \%$ of peak demand. In this designed community microgrid, diesel generator is mostly used to supply emergency loads, i.e., 100kW. The hourly optimal dispatch of BESS, RSPs, and DE along with load shedding are presented in Fig. 11. In this design, the BESS is charged by RSPs with FIT program and then generates revenue by supply the power in absence of RSP generation. The MDE is mostly supplied the night load, including non critical loads.

The proposed two-stage optimisation model for optimal design and operations of community microgrids is investigated for different cases. The proposed mathematical optimisation

\footnotetext{
${ }^{1}$ The permissible average power output over $24 \mathrm{~h}$ of operation shall not exceed $70 \%$ of the prime power
} 


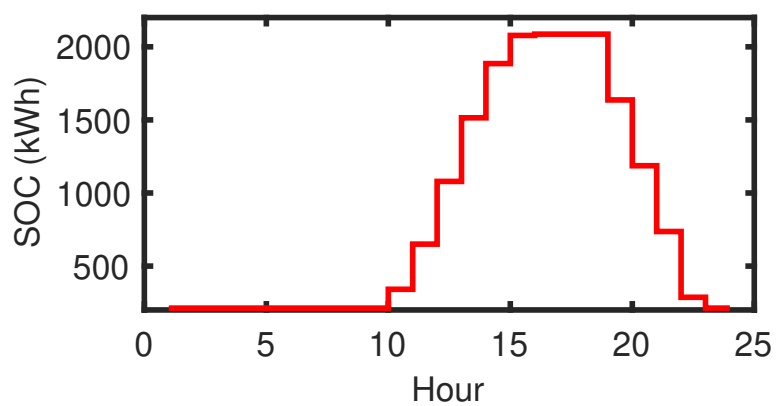

(a)

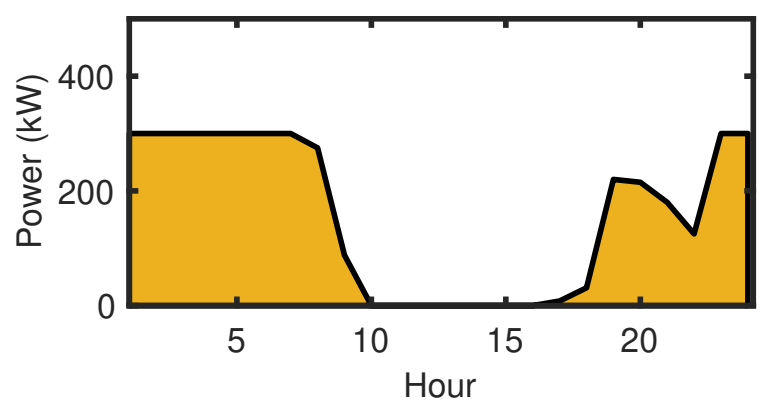

(c)

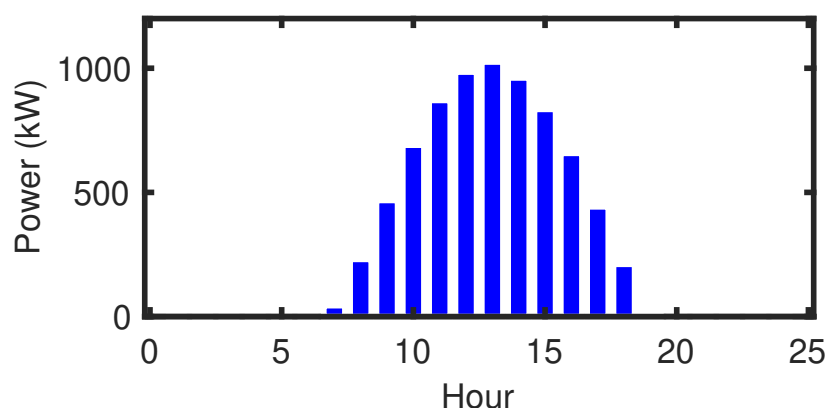

(b)

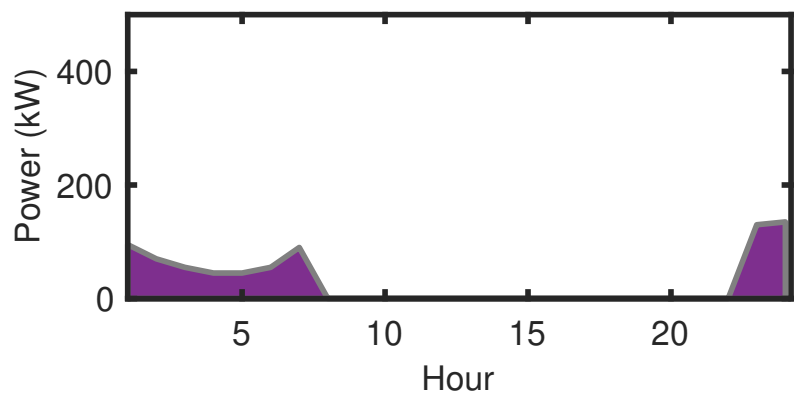

(d)

Figure 11: Optimal dispatch of remote community microgrid: (a) BESS SOC, (b) solar power generation, (c) MDE, and (d) load curtailment

model provides more control on optimisation variables, data, and objectives, in planner and operators desired frameworks, over energy simulation tools. The model is also applicable to real-life communities, to attract third-party investment in community energy systems, under the regulatory framework. As demonstrated that the proposed model provides adequate DER sizes with increased flexibility to operate community systems in off-grid mode, for a long duration. It also facilitates fair competition in local retail electricity markets with increased benefits for all stakeholders with DUoS of network operators. The designed open-market community microgrid design helps to enhance the grid flexibility. The proposed model can have high acceptance in remote communities where consumers highly depend on conventional fuels and find difficulties to invest in clean energy technologies due to their high initial investment. The proposed model can provide a platform to third-party investors to generate long-term profit by investing in DERs. At the same time, the communities can be benefited by minimising their energy bills in retail energy markets. The case study shows that each stakeholder is also able to generate daily revenue under the proposed model varying from $163 £$ to $1251 £$. As per the available data and information, the urban and remote communities would have potential to save $313.71 £$ and $2224.48 £$ respectively on each day which are roughly estimated to be $114504 £$ /year and $811935 £ /$ year respectively, without the initial investment.

\section{Conclusions}


This article presents a sophisticated two-stage optimisation framework for optimal design and operations of urban and remote community microgrids in deregulated environment. The formulation has included multiple layers, mixed-integer optimisation variables, objectives, and constraints. In stage-1, a third-party based investment platform is developed to attract multiple stakeholders to invest in community energy systems comprised of multiple distributed energy resources. A novel P2P based business model has been developed in stage-2 that facilitate active participation of consumers, producers and prosumers with transparent distribution use of the system of network operators. The objectives of the proposed market model and energy management system are to minimise daily operating cost of community systems while maximising benefits of all stakeholders. The proposed model is supported by multiple case studies for urban and remote community microgrids. Results from these case studies revealed that both urban and remote communities have tremendous potential to generate techno-economic benefits but require third-party investment under long-term contract. The designed community microgrids also show the ability to operate in islanding mode, for long duration, under a regulated retail market. Such community market models are beneficiary and necessary at a residential community level, which can avoid a blanket upgrade of the whole network with reduced operational complexity.

The study considered realistic data, programs and ongoing market policies of Ofgem UK, under their initiatives of promoting fair third-party involvement and competitions in the UK energy market, to work for the interests of customer services and system efficiency improvement. The proposed model provides more operational and billing flexibility of modern power consumers in a fully deregulated retail market. One of the promising features of the proposed model is that it does not require initial investments from customers but helps in smart grid policies implementation.

In future, the model can be extended for long-term planning of microgrids with high penetration of EVs, where all EV owners can also be market players under V2X/X2V schemes. Further, a multi-objective optimisation framework may be developed to determine the tradeoff in profit sharing of all stakeholders.

\section{Acknowledgements}

The work is supported by the research projects "Electricity Satnav - Electricity Smart Availability Topology of Network for Abundant electric Vehicles (EPSRC Reference: EP/ R001456/1)" and "Street2Grid - An Electricity Blockchain Platform for P2P Energy Trading (EPSRC Reference: EP/S001778/1)" which are funded by the Engineering and Physical Sciences Research Council (UK Research and Innovation).

\section{References}

[1] World energy outlook 2010 (2010).

[2] K. Geremew, M. Gedefaw, Z. Dagnew, D. Jara, Current level and correlates of traditional cooking energy sources utilization in urban settings in the context of climate change and health, northwest ethiopia: a case of debre markos town, BioMed research international 2014.

[3] Access to electricity (\% of population) (2016). 
[4] M. Arriaga, E. Nasr, H. Rutherford, Renewable energy microgrids in northern remote communities, IEEE Potentials 36 (5) (2017) 22-29.

[5] J. McDowall, Energy storage in remote arctic communities: Driving down diesel consumption with batteries, IEEE Electrification Magazine 6 (3) (2018) 27-33. doi:10.1109/MELE. 2018.2849843.

[6] M. Arriaga, C. A. Cañizares, M. Kazerani, Northern lights: Access to electricity in canada's northern and remote communities, IEEE Power and Energy Magazine 12 (4) (2014) 50-59. doi:10.1109/MPE. 2014.2317963.

[7] M. Ansong, L. D. Mensah, M. S. Adaramola, Techno-economic analysis of a hybrid system to power a mine in an off-grid area in ghana, Sustainable Energy Technologies and Assessments 23 (2017) 48 56. doi:https://doi.org/10.1016/j.seta.2017.09.001.

URL http://www.sciencedirect.com/science/article/pii/S2213138817304721

[8] M. Ranaboldo, B. Domenech, G. A. Reyes, L. Ferrer-Martí, R. P. Moreno, A. García-Villoria, Off-grid community electrification projects based on wind and solar energies: A case study in nicaragua, Solar Energy 117 (2015) 268 - 281. doi:https://doi.org/10.1016/j.solener.2015.05.005.

URL http://www.sciencedirect.com/science/article/pii/S0038092X15002285

[9] G. Venkataramanan, C. Marnay, A larger role for microgrids, IEEE Power and Energy Magazine 6 (3) (2008) 78-82. doi:10.1109/MPE. 2008.918720.

[10] Rural electrification corporation (rec), ministry of power, government of india, "garv grameen vidyutikaran".

URL http://garv.gov.in/dashboard/ue.

[11] Energy access 2017: Achieving energy for all by 2030 (2017).

[12] D. Kuo, Water, food, energy...the very basic needs of seven billion souls, Independent. URL https://www.independent.co.uk

[13] J. S. Lacerda, J. C. van den Bergh, Mismatch of wind power capacity and generation: causing factors, ghg emissions and potential policy responses, Journal of cleaner production 128 (2016) 178-189.

[14] N. K. Meena, A. Swarnkar, N. Gupta, K. R. Niazi, A taguchi-based approach for optimal placement of distributed generations for power loss minimization in distribution system, in: 2015 IEEE Power Energy Society General Meeting, 2015, pp. 1-5. doi:10.1109/PESGM.2015.7286180.

[15] N. K. Meena, A. Swarnkar, N. Gupta, K. R. Niazi, Optimal integration of ders in coordination with existing vrs in distribution networks, IET Generation, Transmission Distribution 12 (11) (2018) 25202529. doi:10.1049/iet-gtd.2017.1403.

[16] M. Esmaili, E. C. Firozjaee, H. A. Shayanfar, Optimal placement of distributed generations considering voltage stability and power losses with observing voltage-related constraints, Applied Energy 113 (2014) 1252 - 1260. doi:https://doi.org/10.1016/j.apenergy.2013.09.004.

URL http://www.sciencedirect.com/science/article/pii/S030626191300740X

[17] T. V. Kusumadewi, P. Winyuchakrit, B. Limmeechokchai, Long-term co2 emission reduction from renewable energy in power sector: The case of thailand in 2050, Energy Procedia 138 (2017) 961 - 966. doi:https://doi.org/10.1016/j.egypro.2017.10.089.

[18] A. J. Veldhuis, M. Leach, A. Yang, The impact of increased decentralised generation on the reliability of an existing electricity network, Applied Energy 215 (2018) 479 - 502. doi:https://doi.org/10. 1016/j . apenergy . 2018.02.009.

[19] A. Aram, Microgrid market in the usa, Global Innovation Report (2017) 2630.

[20] N. K. Meena, A. Swarnkar, N. Gupta, K. R. Niazi, Stochastic volt/var planning and operation for microgrids with renewables, International Journal of Electrical Energy 4 (3) (2016) 159-164. doi: 10.18178/ijoee.4.3.159-164.

[21] M. Stadler, G. Cardoso, S. Mashayekh, T. Forget, N. DeForest, A. Agarwal, A. Schönbein, Value streams in microgrids: A literature review, Applied Energy 162 (2016) 980 - 989. doi:https://doi. org $/ 10.1016 / j$. apenergy . 2015.10.081.

URL http://www.sciencedirect.com/science/article/pii/S0306261915013082

[22] Q. Fu, A. Nasiri, A. Solanki, A. Bani-Ahmed, L. Weber, V. Bhavaraju, Microgrids: Architectures, controls, protection, and demonstration, Electric Power Components and Systems 43 (12) (2015) 1453- 
1465. arXiv:https://doi.org/10.1080/15325008.2015.1039098, doi:10.1080/15325008.2015. 1039098.

URL https://doi.org/10.1080/15325008.2015.1039098

[23] K. Ravindra, P. P. Iyer, Decentralized demand-supply matching using community microgrids and consumer demand response: A scenario analysis, Energy 76 (2014) 32 - 41. doi:https://doi.org/ 10.1016/j.energy.2014.02.043.

[24] U. Mukherjee, A. Maroufmashat, J. Ranisau, M. Barbouti, A. Trainor, N. Juthani, H. El-Shayeb, M. Fowler, Techno-economic, environmental, and safety assessment of hydrogen powered community microgrids; case study in canada, International Journal of Hydrogen Energy 42 (20) (2017) 14333 14349. doi:https://doi.org/10.1016/j.ijhydene.2017.03.083.

URL http://www.sciencedirect.com/science/article/pii/S0360319917310078

[25] L. Wu, T. Ortmeyer, J. Li, The community microgrid distribution system of the future, The Electricity Journal 29 (10) (2016) 16-21. doi:https://doi.org/10.1016/j.tej.2016.11.008. URL http://www.sciencedirect.com/science/article/pii/S1040619016302123

[26] A. H. Hajimiragha, M. R. D. Zadeh, Research and development of a microgrid control and monitoring system for the remote community of bella coola: Challenges, solutions, achievements and lessons learned, in: 2013 IEEE International Conference on Smart Energy Grid Engineering (SEGE), 2013, pp. 1-6. doi:10.1109/SEGE.2013.6707898.

[27] X. Lu, S. Bahramirad, J. Wang, C. Chen, Bronzeville community microgrids: A reliable, resilient and sustainable solution for integrated energy management with distribution systems, The Electricity Journal 28 (10) (2015) 29 -42. doi:https://doi.org/10.1016/j.tej.2015.11.009. URL http://www.sciencedirect.com/science/article/pii/S1040619015002481

[28] N. K. Meena, S. Parashar, A. Swarnkar, N. Gupta, K. Niazi, R. Bansal, Mobile power infrastructure planning and operational management for smart city applications, Energy Procedia 142 (2017) 2202 2207, proceedings of the 9th International Conference on Applied Energy. doi:https://doi.org/10. 1016/j .egypro.2017.12.589.

[29] T. Bourgeois, J. Gerow, F. Litz, N. Martin, Community microgrids: Smarter, cleaner, greener, Pace Energy and Climate Center, Pace Law School, White Plains, NY.

[30] Virtue energy storage: a complete integrated energy storage and microgrid solution with smart grid control for behind-the-meter applications.

URL https://powerstar.com/virtue/benefits/

[31] Energy storage is a $\$ 620$ billion investment opportunity to 2040.

URL https://about.bnef .com

[32] K. Sharma, D. V. Shah, Supercharged: Challenges and opportunities in global battery storage markets (2018). URL https://www2.deloitte.com

[33] P. Moutis, S. Skarvelis-Kazakos, M. Brucoli, Decision tree aided planning and energy balancing of planned community microgrids, Applied Energy 161 (2016) 197 - 205. doi:https://doi.org/10. 1016/j . apenergy .2015.10.002.

[34] C. Yuan, M. S. Illindala, A. S. Khalsa, Co-optimization scheme for distributed energy resource planning in community microgrids, IEEE Transactions on Sustainable Energy 8 (4) (2017) 1351-1360. doi: 10.1109/TSTE. 2017.2681111.

[35] C. Kirubi, A. Jacobson, D. M. Kammen, A. Mills, Community-based electric micro-grids can contribute to rural development: evidence from kenya, World Development 37 (7) (2009) 1208 - 1221. doi: https: //doi.org/10.1016/j.worlddev.2008.11.005.

[36] J. Cao, C. Crozier, M. McCulloch, Z. Fan, Optimal design and operation of a low carbon community based multi-energy systems considering ev integration, IEEE Transactions on Sustainable Energy.

[37] M. Sameti, F. Haghighat, A two-level multi-objective optimization for simultaneous design and scheduling of a district energy system, Applied Energy 208 (2017) 1053 - 1070. doi:https://doi.org/10. 1016/j . apenergy . 2017.09.046.

URL http://www.sciencedirect.com/science/article/pii/S0306261917313272 
[38] C. Ghenai, T. Salameh, A. Merabet, Technico-economic analysis of off grid solar pv/fuel cell energy system for residential community in desert region, International Journal of Hydrogen Energydoi: https://doi.org/10.1016/j.ijhydene.2018.05.110.

URL http://www.sciencedirect.com/science/article/pii/S0360319918316550

[39] F. Alavi, E. P. Lee, N. van de Wouw, B. D. Schutter, Z. Lukszo, Fuel cell cars in a microgrid for synergies between hydrogen and electricity networks, Applied Energy 192 (2017) 296 - 304. doi: https://doi.org/10.1016/j. apenergy . 2016.10.084.

URL http://www.sciencedirect.com/science/article/pii/S0306261916315288

[40] Y.-Y. Hong, W.-C. Chang, Y.-R. Chang, Y.-D. Lee, D.-C. Ouyang, Optimal sizing of renewable energy generations in a community microgrid using markov model, Energy 135 (2017) 68 - 74. doi:https: //doi.org/10.1016/j. energy.2017.06.098.

URL http://www.sciencedirect.com/science/article/pii/S0360544217310927

[41] P. Peerapong, B. Limmeechokchai, Optimal electricity development by increasing solar resources in diesel-based micro grid of island society in thailand, Energy Reports 3 (2017) 1 - 13. doi:https: //doi.org/10.1016/j.egyr.2016.11.001.

URL http://www.sciencedirect.com/science/article/pii/S2352484716300634

[42] W. Setthapun, S. Srikaew, J. Rakwichian, N. Tantranont, W. Rakwichian, R. Singh, The integration and transition to a dc based community: A case study of the smart community in chiang mai world green city, in: 2015 IEEE First International Conference on DC Microgrids (ICDCM), 2015, pp. 205209. doi:10.1109/ICDCM. 2015.7152039.

[43] M. Arriaga, C. A. Caizares, M. Kazerani, Long-term renewable energy planning model for remote communities, IEEE Transactions on Sustainable Energy 7 (1) (2016) 221-231. doi:10.1109/TSTE. 2015.2483489.

[44] N. K. Meena, A. Swarnkar, N. Gupta, K. R. Niazi, An uvlo featured average current mode controlled boost converter design for automotive industry applications, in: 2016 IEEE 1st International Conference on Power Electronics, Intelligent Control and Energy Systems (ICPEICES), 2016, pp. 1-6. doi: 10.1109/ICPEICES. 2016.7853453.

[45] R. Langella, A. Testa, J. Meyer, F. Möller, R. Stiegler, S. Z. Djokic, Experimental-based evaluation of pv inverter harmonic and interharmonic distortion due to different operating conditions, IEEE Transactions on Instrumentation and Measurement 65 (10) (2016) 2221-2233. doi:10.1109/TIM. 2016. 2554378.

[46] Electromagnetic compatibility (emc)-part 3-15: Limits-assessment of low frequency electromagnetic immunity and emission requirements for dispersed generation systems in lv network. doi: IECStandard61000-3-15:2011.

[47] M. Khodaparastan, H. Vahedi, F. Khazaeli, H. Oraee, A novel hybrid islanding detection method for inverter-based dgs using sfs and rocof, IEEE Transactions on Power Delivery 32 (5) (2017) 2162-2170. doi:10.1109/TPWRD. 2015.2406577.

[48] P. M. Kishore, R. Bhimasingu, A non-isolated single stage three-port converter for hybrid microgrid applications, in: 2016 First International Conference on Sustainable Green Buildings and Communities (SGBC), 2016, pp. 1-6. doi:10.1109/SGBC.2016.7936057.

[49] Z. Xu, P. Yang, C. Zheng, Y. Zhang, J. Peng, Z. Zeng, Analysis on the organization and development of multi-microgrids, Renewable and Sustainable Energy Reviews 81 (2018) 2204 - 2216. doi:https: //doi.org/10.1016/j.rser.2017.06.032.

URL http://www.sciencedirect.com/science/article/pii/S1364032117309723

[50] H. Haddadian, R. Noroozian, Multi-microgrids approach for design and operation of future distribution networks based on novel technical indices, Applied Energy 185 (2017) 650 - 663. doi:https://doi. org $/ 10.1016 / j$. apenergy . 2016.10.120.

URL http://www.sciencedirect.com/science/article/pii/S0306261916315690

[51] C. Wouters, Towards a regulatory framework for microgrids - the singapore experience, Sustainable Cities and Society 15 (2015) 22 -32. doi:https://doi.org/10.1016/j.scs.2014.10.007. URL http://www.sciencedirect.com/science/article/pii/S2210670714001152 
[52] K. Chen, M. Baran, Stability of a community microgrid in islanded mode: A case study, in: 2018 9th IEEE International Symposium on Power Electronics for Distributed Generation Systems (PEDG), 2018, pp. 1-5. doi:10.1109/PEDG. 2018.8447735.

[53] C.-X. Dou, D.-L. Liu, X.-B. Jia, F. Zhao, Management and control for smart microgrid based on hybrid control theory, Electric Power Components and Systems 39 (8) (2011) 813-832. arXiv:https: //doi.org/10.1080/15325008.2010.541414, doi:10.1080/15325008.2010.541414. URL https://doi.org/10.1080/15325008.2010.541414

[54] X. Feng, A. Shekhar, F. Yang, R. E. Hebner, P. Bauer, Comparison of hierarchical control and distributed control for microgrid, Electric Power Components and Systems 45 (10) (2017) 10431056. arXiv:https://doi.org/10.1080/15325008.2017.1318982, doi:10.1080/15325008.2017. 1318982.

URL https://doi.org/10.1080/15325008.2017.1318982

[55] Q. Long, Y. Du, J. Lu, D. Lubkeman, S. Lukic, N. Lu, J. S. Camilleri, Community microgrid controller evaluation using hardware-in-the-loop testbed, in: 2018 North American Power Symposium (NAPS), 2018, pp. 1-6. doi:10.1109/NAPS.2018.8600556.

[56] X. Wang, C. Wang, T. Xu, L. Guo, P. Li, L. Yu, H. Meng, Optimal voltage regulation for distribution networks with multi-microgrids, Applied Energy 210 (2018) 1027 - 1036. doi:https://doi.org/10. 1016/j . apenergy . 2017.08.113.

URL http://www.sciencedirect.com/science/article/pii/S0306261917311376

[57] J. Yan, M. Menghwar, E. Asghar, M. K. Panjwani, Y. Liu, Real-time energy management for a smartcommunity microgrid with battery swapping and renewables, Applied Energy 238 (2019) 180 - 194. doi:https://doi.org/10.1016/j . apenergy . 2018.12.078.

URL http://www.sciencedirect.com/science/article/pii/S0306261918318889

[58] L. Che, M. Shahidehpour, A. Alabdulwahab, Y. Al-Turki, Hierarchical coordination of a community microgrid with ac and dc microgrids, IEEE Transactions on Smart Grid 6 (6) (2015) 3042-3051. doi: 10.1109/TSG.2015.2398853.

[59] R. Jha, N. K. Meena, A. Swarnkar, N. Gupta, K. R. Niazi, Dynamic economic dispatch of micro-grid using harmony search algorithm, in: 2015 Annual IEEE India Conference (INDICON), 2015, pp. 1-6. doi:10.1109/INDICON.2015.7443330.

[60] C. Long, J. Wu, Y. Zhou, N. Jenkins, Peer-to-peer energy sharing through a two-stage aggregated battery control in a community microgrid, Applied Energy 226 (2018) 261 - 276. doi:https://doi. org $/ 10.1016 / j$. apenergy . 2018.05.097.

URL http://www.sciencedirect.com/science/article/pii/S0306261918308146

[61] T. Madiba, R. C. Bansal, Optimal load-shedding control of a microgrid power system, Electric Power Components and Systems 46 (7) (2018) 768-787. arXiv:https://doi.org/10.1080/15325008.2018. 1501622, doi:10.1080/15325008.2018.1501622.

URL https://doi.org/10.1080/15325008.2018.1501622

[62] M. Sameti, F. Haghighat, Integration of distributed energy storage into net-zero energy district systems: Optimum design and operation, Energy 153 (2018) 575 - 591. doi:https://doi.org/10.1016/j. energy. 2018.04.064.

URL http://www.sciencedirect.com/science/article/pii/S0360544218306716

[63] R. Davies, M. Sumner, E. Christopher, Energy storage control for a small community microgrid, in: 7th IET International Conference on Power Electronics, Machines and Drives (PEMD 2014), 2014, pp. 1-6. doi:10.1049/cp.2014.0508.

[64] P. Shamsi, H. Xie, A. Longe, J. Joo, Economic dispatch for an agent-based community microgrid, IEEE Transactions on Smart Grid 7 (5) (2016) 2317-2324. doi:10.1109/TSG.2015.2487422.

[65] A. H. Fathima, K. Palanisamy, Optimization in microgrids with hybrid energy systems - a review, Renewable and Sustainable Energy Reviews 45 (2015) 431 - 446. doi:https://doi.org/10.1016/j. rser.2015.01.059.

URL http://www.sciencedirect.com/science/article/pii/S1364032115000696

[66] M. Sameti, F. Haghighat, Optimization approaches in district heating and cooling thermal network, 
Energy and Buildings 140 (2017) 121 - 130. doi:https://doi.org/10.1016/j.enbuild.2017.01. 062.

URL http://www.sciencedirect.com/science/article/pii/S0378778816312245

[67] Z. Su, Y. Wang, Q. Xu, M. Fei, Y. Tian, N. Zhang, A secure charging scheme for electric vehicles with smart communities in energy blockchain, IEEE Internet of Things Journal (2019) 1-1doi:10.1109/ JIOT. 2018.2869297.

[68] V. R. Disfani, L. Fan, L. Piyasinghe, Z. Miao, Multi-agent control of community and utility using lagrangian relaxation based dual decomposition, Electric Power Systems Research 110 (2014) $45-54$. doi:https://doi.org/10.1016/j.epsr.2014.01.009.

[69] X. Jing, L. Hong, X. Ke, L. Jifeng, W. Shiju, Y. Zan, W. Bo, Synergistic scheduling in integrated community energy system considering wind power accommodation, Energy Procedia 145 (2018) 211 216, renewable Energy Integration with Mini/Microgrid. doi:https://doi.org/10.1016/j.egypro. 2018.04 .037$.

URL http://www.sciencedirect.com/science/article/pii/S1876610218300420

[70] A. Khodaei, M. Shahidehpour, J. Choi, Optimal hourly scheduling of community-aggregated electricity consumption, Journal of Electrical Engineering and Technology 8 (6) (2013) 1251-1260.

[71] M. Sameti, F. Haghighat, Hybrid solar and heat-driven district cooling system: Optimal integration and control strategy, Solar Energy 183 (2019) 260 -275. doi:https://doi.org/10.1016/j.solener. 2019.03 .034$.

URL http://www.sciencedirect.com/science/article/pii/S0038092X19302609

[72] B. Hu, H. Wang, S. Yao, Optimal economic operation of isolated community microgrid incorporating temperature controlling devices, Protection and Control of Modern Power Systems 2 (1) (2017) 6 . doi:10.1186/s41601-017-0037-1.

URL https://doi.org/10.1186/s41601-017-0037-1

[73] S. Nguyen, W. Peng, P. Sokolowski, D. Alahakoon, X. Yu, Optimizing rooftop photovoltaic distributed generation with battery storage for peer-to-peer energy trading, Applied Energy 228 (2018) 2567 2580. doi:https://doi.org/10.1016/j.apenergy.2018.07.042.

[74] S. A. Helal, R. J. Najee, M. O. Hanna, M. F. Shaaban, A. H. Osman, M. S. Hassan, An energy management system for hybrid microgrids in remote communities, in: 2017 IEEE 30th Canadian Conference on Electrical and Computer Engineering (CCECE), 2017, pp. 1-4. doi:10.1109/CCECE.2017.7946775.

[75] M. Sameti, F. Haghighat, Optimization of 4th generation distributed district heating system: Design and planning of combined heat and power, Renewable Energy 130 (2019) 371 - 387. doi:https: //doi.org/10.1016/j.renene.2018.06.068.

URL http://www.sciencedirect.com/science/article/pii/S0960148118307201

[76] S. Noor, W. Yang, M. Guo, K. H. van Dam, X. Wang, Energy demand side management within micro-grid networks enhanced by blockchain, Applied Energy 228 (2018) 1385 - 1398. doi:https:

//doi.org/10.1016/j. apenergy.2018.07.012.

URL http://www.sciencedirect.com/science/article/pii/S0306261918310390

[77] M. Motalleb, R. Ghorbani, Non-cooperative game-theoretic model of demand response aggregator competition for selling stored energy in storage devices, Applied Energy 202 (2017) 581 - 596. doi:https://doi.org/10.1016/j. apenergy.2017.05.186.

URL http://www.sciencedirect.com/science/article/pii/S0306261917307481

[78] C. Zhang, J. Wu, Y. Zhou, M. Cheng, C. Long, Peer-to-peer energy trading in a microgrid, Applied Energy 220 (2018) 1 -12. doi:https://doi.org/10.1016/j.apenergy .2018.03.010. URL http://www.sciencedirect.com/science/article/pii/S0306261918303398

[79] G. Liu, T. Jiang, T. B. Ollis, X. Zhang, K. Tomsovic, Distributed energy management for community microgrids considering network operational constraints and building thermal dynamics, Applied Energy 239 (2019) 83 - 95. doi:https://doi.org/10.1016/j.apenergy.2019.01.210.

URL http://www.sciencedirect.com/science/article/pii/S0306261919302314

[80] Electricity retail markets, office of gas and electricity markets, uk. URL https://www . of gem.gov.uk/electricity/retail-market 
[81] J. Hwang, M. in Choi, T. Lee, S. Jeon, S. Kim, S. Park, S. Park, Energy prosumer business model using blockchain system to ensure transparency and safety, Energy Procedia 141 (2017) 194 - 198, power and Energy Systems Engineering. doi:https://doi.org/10.1016/j.egypro.2017.11.037. URL http://www.sciencedirect.com/science/article/pii/S1876610217354437

[82] C. Long, J. Wu, C. Zhang, M. Cheng, A. Al-Wakeel, Feasibility of peer-to-peer energy trading in low voltage electrical distribution networks, Energy Procedia 105 (2017) 2227 - 2232. doi:https: //doi.org/10.1016/j.egypro.2017.03.632.

[83] C. Zhang, J. Wu, M. Cheng, Y. Zhou, C. Long, A bidding system for peer-to-peer energy trading in a grid-connected microgrid, Energy Procedia 103 (2016) 147 - 152. doi:https://doi.org/10.1016/j. egypro.2016.11.264.

[84] C. Zhang, J. Wu, C. Long, M. Cheng, Review of existing peer-to-peer energy trading projects, Energy Procedia 105 (2017) 2563 - 2568. doi:https://doi.org/10.1016/j.egypro.2017.03.737.

[85] A. Paudel, G. H. Beng, A hierarchical peer-to-peer energy trading in community microgrid distribution systems, in: 2018 IEEE Power Energy Society General Meeting (PESGM), 2018, pp. 1-5. doi:10. 1109/PESGM. 2018.8586168.

[86] Z. Huang, H. Yu, Z. Peng, Y. Feng, Planning community energy system in the industry 4.0 era: Achievements, challenges and a potential solution, Renewable and Sustainable Energy Reviews 78 (2017) $710-721$. doi:https://doi.org/10.1016/j.rser.2017.04.004.

URL http://www.sciencedirect.com/science/article/pii/S1364032117304768

[87] Y. Zhou, J. Wu, C. Long, Evaluation of peer-to-peer energy sharing mechanisms based on a multiagent simulation framework, Applied Energy 222 (2018) 993 - 1022. doi:https://doi.org/10.1016/j. apenergy . 2018.02.089.

URL http://www.sciencedirect.com/science/article/pii/S0306261918302149

[88] A. Patel, H. K. Nunna, S. Doolla, Multi-agent-based forecast update methods for profit enhancement of intermittent distributed generators in a smart microgrid, Electric Power Components and Systems 0 (0) (2018) 1-13. arXiv:https://doi.org/10.1080/15325008.2018.1517838, doi:10.1080/15325008. 2018.1517838.

URL https://doi.org/10.1080/15325008.2018.1517838

[89] J. Li, Y. Liu, L. Wu, Optimal operation for community-based multi-party microgrid in grid-connected and islanded modes, IEEE Transactions on Smart Grid 9 (2) (2018) 756-765. doi:10.1109/TSG. 2016. 2564645.

[90] E. Mengelkamp, J. Gärttner, K. Rock, S. Kessler, L. Orsini, C. Weinhardt, Designing microgrid energy markets: A case study: The brooklyn microgrid, Applied Energy 210 (2018) 870 - 880. doi:https: //doi.org/10.1016/j. apenergy.2017.06.054.

URL http://www.sciencedirect.com/science/article/pii/S030626191730805X

[91] Ofgem proposes new regulatory framework for network companies, Electricity Retail Markets, Office of Gas and Electricity Markets, UK. URL https://www. of gem.gov. uk

[92] N. K. Meena, A. Swarnkar, N. Gupta, K. R. Niazi, Optimal accommodation and management of high renewable penetration in distribution systems, The Journal of Engineering 2017 (13) (2017) 1890-1895. doi:10.1049/joe.2017.0659.

[93] G. Reid, G. Wynn, The future of solar power in the united kingdom, Energies 8 (8) (2015) 7818-7832. doi: $10.3390 /$ en8087818.

[94] N. K. Meena, A. Swarnkar, N. Gupta, K. R. Niazi, Dispatchable solar photovoltaic power generation planning for distribution systems, in: 2017 IEEE International Conference on Industrial and Information Systems (ICIIS), 2017, pp. 1-6. doi:10.1109/ICIINFS.2017.8300337.

[95] A. Swarnkar, N. Gupta, K. Niazi, A novel codification for meta-heuristic techniques used in distribution network reconfiguration, Electric Power Systems Research 81 (7) (2011) 1619 - 1626. doi:https: //doi.org/10.1016/j.epsr.2011.03.020.

URL http://www.sciencedirect.com/science/article/pii/S0378779611000836

[96] Koel green is the genset brand of kirloskar oil engines ltd (koel). 
URL http://www.koelgreen.com

[97] 913 kva mtu gsw 1000m pramac mtu open generator $913 \mathrm{kva}$.

URL https://dieselgeneratordirect.uk/power-generators/913-kva-mtu.html

Appendix A. Optimized parameters of urban and community microgrids 


\begin{tabular}{|c|c|c|c|c|c|c|c|c|c|c|c|c|c|c|c|c|c|c|c|c|c|c|c|}
\hline ה & 0 & $\rightarrow$ & & $\dashv$ & $\dashv$ & חֶ & 0 & 0 & $\dashv$ & -1 & $\dashv$ & $\neg$ & $\overrightarrow{\widetilde{o}}$ & 0 & 0 & & 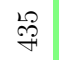 & $0-1$ & -1 & & 0 & & \&్ల \\
\hline$\stackrel{\sim}{\sim}$ & 0 & $\rightarrow$ & & - & 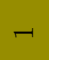 & م) & 0 & 0 & - & - & - & $\rightarrow$ & 蛋 & 0 & 0 & - & 㕝 & $0-1$ & -1 & -1 & - & - & 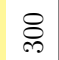 \\
\hline ลิ & 0 & $\rightarrow \quad$ & - & $\dashv$ & $\dashv$ & $\widehat{\hat{p}}$ & 0 & 0 & $\neg$ & - & $\dashv$ & - & ڤึ & 0 & 0 & $\dashv$ & 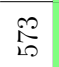 & $0-1$ & -1 & -1 & $\rightarrow$ 孪 & $\dashv$ & $\stackrel{\stackrel{2}{9}}{\cong}$ \\
\hline$\vec{\sim}$ & 0 & $\rightarrow$ & & $\neg$ & $\neg$ & ৯ & $\rightarrow$ & 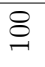 & $\neg$ & - & $\dashv$ & $\dashv$ & $\stackrel{g}{F}$ & - & $\stackrel{8}{\circ}$ & - & $\stackrel{\infty}{0}$ & $0-1$ & - & -1 & 一察 & $\dashv$ & $\underset{\sim}{\infty}$ \\
\hline ๙ิ & 0 & $\neg \quad$ & - & - & $\neg$ & $\stackrel{8}{7}$ & $\neg$ & $\stackrel{\wp}{Ð}$ & $\neg$ & $\neg$ & $\neg$ & $\neg$ & 㝵 & - & 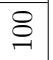 & - & ठृ & $0 \quad-1$ & -1 & -1 & - & - & $\stackrel{20}{\vec{N}}$ \\
\hline$\stackrel{9}{2}$ & 0 & $-\quad$ & - & $\dashv$ & & 点 & $\neg$ & 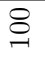 & $\dashv$ & - & - & - & 品 & - & 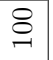 & - & \&్రి & $0-1$ & -1 & -1 & -1 蛋 & $\dashv$ & స్ \\
\hline$\stackrel{\infty}{=}$ & 0 & - & & - & - & F & - & $\stackrel{-}{\circ}$ & $\neg$ & - & - & - & 紊 & - & 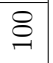 & - & \&్రి & $0 \quad-1$ & -1 & - & $\stackrel{\infty}{\exists}$ & - & $\vec{\infty}$ \\
\hline$\cong$ & 0 & $\rightarrow$ & - & $\dashv$ & $\neg$ & 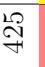 & 0 & 0 & $\neg$ & - & - & - & 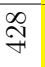 & $\neg$ & r & - & $\ddot{0}$ & $0-1$ & -1 & - & 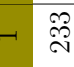 & $\neg$ & $\infty$ \\
\hline$\stackrel{0}{-1}$ & 0 & - & & $\dashv$ & $\neg$ & 点 & 0 & 0 & $\neg$ & - & - & - & ॄू. & $\neg$ & $\stackrel{\infty}{\sim}$ & $\neg$ & ?ి & $0 \quad-1$ & -1 & -1 & $-\sigma_{i}$ & 0 & 0 \\
\hline$\stackrel{20}{\sim}$ & 0 & $-r$ & & $\dashv$ & - & I & 0 & 0 & $\dashv$ & $\neg$ & - & $\rightarrow$ & $\stackrel{\infty}{\stackrel{\wp}{9}}$ & $\neg$ & $\mathscr{\infty}$ & $\neg$ & ซี & $0-1$ & -1 & - & $-\stackrel{\mathscr{m}}{\rightarrow}$ & 0 & 0 \\
\hline$\exists$ & 0 & $-r$ & & $\dashv$ & $\neg$ & 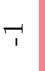 & 0 & 0 & $\neg$ & - & $\dashv$ & $\rightarrow$ & $\stackrel{\sim}{\sim}$ & $\neg$ & $\overleftrightarrow{N}$ & $\dashv$ & 量 & $0-1$ & -1 & -1 & $-\underset{\infty}{F}$ & 0 & 0 \\
\hline 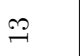 & 0 & $-r$ & & $\dashv$ & 0 & 0 & 0 & 0 & $\neg$ & - & $\dashv$ & $\rightarrow$ & $\exists$ & $\neg$ & 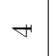 & - & 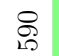 & $0-1$ & -1 & -1 & $\stackrel{\llcorner}{\stackrel{4}{7}}$ & 0 & 0 \\
\hline 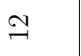 & 0 & $-r$ & & - & & 0 & 0 & 0 & $\neg$ & - & - & - & $\infty$ & 0 & 0 & - & $\begin{array}{l}20 \\
2 \\
2\end{array}$ & $0-1$ & -1 & -1 & 辛 & 0 & 0 \\
\hline$\exists$ & 0 & - & & $\dashv$ & - & $r$ & 0 & 0 & $\neg$ & - & $\dashv$ & - & $\stackrel{\infty}{\leftrightarrow}$ & - & $\stackrel{2}{N}$ & - & $\overrightarrow{0}$ & $0-1$ & -1 & -1 & के & 0 & 0 \\
\hline ? & 0 & $-r$ & & - & $\neg$ & P & 0 & 0 & $\neg$ & - & - & $\rightarrow$ & 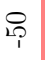 & 0 & 0 & - & $\vec{b}$ & $0-1$ & - & - & 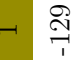 & 0 & 0 \\
\hline o & 0 & $\rightarrow-$ & & - & $\neg$ & L & 0 & 0 & $\neg$ & - & - & $\neg$ & $\&_{1}$ & 0 & 0 & - & 虽 & $0-1$ & - & - & 0 & - & $\begin{array}{l}\infty \\
\infty\end{array}$ \\
\hline$\infty$ & 0 & $-r$ & - & - & - & $\overrightarrow{\mathcal{F}}$ & 0 & 0 & $\neg$ & - & $\dashv$ & - & .̊. & 0 & 0 & - & 寗 & $0-1$ & -1 & - & 0 & - & 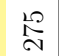 \\
\hline r & 0 & -1 & & - & - & ח̊ & 0 & 0 & $\neg$ & - & 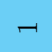 & $\rightarrow$ & 足 & 0 & 0 & - & 営 & $0-1$ & -1 & - & 0 & - & ి్ \\
\hline 0 & 0 & $\rightarrow$ & & $\dashv$ & - & ָิ & 0 & 0 & - & $\rightarrow$ & $\dashv$ & - & $\overbrace{i}$ & 0 & 0 & $\neg$ & $\vec{D}$ & $0 \quad-1$ & -1 & -1 & 0 & - & \&్ల \\
\hline 10 & 0 & $\neg \quad$ & & $\dashv$ & $\neg$ & ָิ & 0 & 0 & $\dashv$ & - & $\dashv$ & - & ז & 0 & 0 & -1 & $\stackrel{29}{6}$ & $0-1$ & - & -1 & 0 & $\neg$ & \&్ల \\
\hline 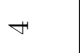 & 0 & $\rightarrow \quad$ & & - & $\neg$ & $\stackrel{\infty}{\Rightarrow}$ & 0 & 0 & $\neg$ & - & - & - & 点 & 0 & 0 & - & 点 & $0-1$ & -1 & - & 0 & & ి̊ \\
\hline$\infty$ & 0 & $-r$ & & $\dashv$ & $\dashv$ & $\stackrel{8}{-}$ & 0 & 0 & $\neg$ & - & $\dashv$ & $\rightarrow$ & $\overrightarrow{\widetilde{p}}$ & 0 & 0 & - & 点 & $0 \quad-1$ & -1 & -1 & 0 & & 尺ి \\
\hline ก & 0 & $-r$ & & $\dashv$ & $\neg$ & 喊 & 0 & 0 & - & - & $\dashv$ & $\rightarrow$ & $\overrightarrow{\text { ज }}$ & 0 & 0 & - & : & $0-1$ & -1 & - & 0 & - & \&్ల \\
\hline- & 0 & $\rightarrow \quad$ & - & $\dashv$ & - & F & 0 & 0 & 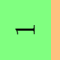 & - & - & $\rightarrow$ & 唯 & 0 & 0 & $\neg$ & ઼్ & $0 \quad-1$ & -1 & -1 & 0 & - & ి̊ \\
\hline 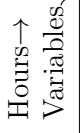 & $\begin{array}{l}\uparrow \\
Q\end{array}$ & $\begin{array}{l}\uparrow \\
\sigma\end{array}$ & & $\begin{array}{l}\uparrow \\
\succ\end{array}$ & $\begin{array}{l}\uparrow \\
\text { ws }\end{array}$ & 常 & $\begin{array}{l}\uparrow \\
\Varangle\end{array}$ & $\frac{\sum_{a}}{\frac{\pi}{2}}$ & $\begin{array}{l}\uparrow \\
\gamma\end{array}$ & $\begin{array}{l}\uparrow \\
\infty\end{array}$ & $\begin{array}{l}\uparrow \\
\succ\end{array}$ & $\begin{array}{l}\uparrow \\
w\end{array}$ & 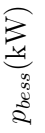 & $\underset{x}{\uparrow}$ & $\begin{array}{l}\underset{3}{\frac{\pi}{z}} \\
\frac{\pi}{2}\end{array}$ & & $\begin{array}{c}\widehat{z} \\
\substack{a \\
\frac{a}{2}}\end{array}$ & $\begin{array}{ll}\uparrow & \uparrow \\
\gamma & \infty\end{array}$ & $\begin{array}{r}\uparrow \\
b\end{array}$ & $\uparrow$ & 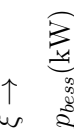 & ${ }_{x}$ & $\frac{\vec{z}}{\frac{3}{2}}$ \\
\hline \multirow{2}{*}{ 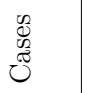 } & - & & & & $\exists$ & & & & & & & $\Xi$ & & & & 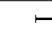 & F & & & & $\exists$ & & \\
\hline & \multicolumn{15}{|c|}{ 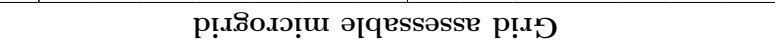 } & \multicolumn{8}{|c|}{ р!...оолэ!ш әұошәप } \\
\hline
\end{tabular}

